\title{
Factors Affecting Acoustic Properties of Natural-Fiber-Based Materials and Composites: A Review
}

\author{
Tufail Hassan ${ }^{1,+}$, Hafsa Jamshaid ${ }^{1}$, Rajesh Mishra ${ }^{2, *}+{ }^{(\mathbb{D}}$, , Muhammad Qamar Khan ${ }^{3}$, Michal Petru $^{4}$ (D), \\ Martin Tichy ${ }^{2}$ and Miroslav Muller ${ }^{2}$ (D)
}

1 Protective Textile Group, Faculty of Textile Engineering, Department of Fabric Manufacturing, National Textiles University, Faisalabad 37610, Pakistan; tufailhassan12@gmail.com (T.H.); hafsa@ntu.edu.pk (H.J.)

2 Faculty of Engineering, Czech University of Life Sciences Prague, Kamýcká 129, 16500 Praha-Suchdol, Czech Republic; martintichy@tf.czu.cz (M.T.); muller@tf.czu.cz (M.M.)

3 Department of Textile and Clothing, National Textile University Karachi Campus, Karachi 74900, Pakistan; qamarkhan154@gmail.com

4 Faculty of Mechanical Engineering, Technical University of Liberec, Studentska 2, 46117 Liberec, Czech Republic; michal.petru@tul.cz

* Correspondence: mishrar@tf.czu.cz

+ These authors contributed equally.

check for updates

Citation: Hassan, T.; Jamshaid, H.; Mishra, R.; Khan, M.Q.; Petru, M.; Tichy, M.; Muller, M. Factors

Affecting Acoustic Properties of Natural-Fiber-Based Materials and Composites: A Review. Textiles 2021, 1,55-85. https://doi.org/ $10.3390 /$ textiles 1010005

Academic Editors: Philippe Boisse and Stepan Lomov

Received: 16 March 2021

Accepted: 26 May 2021

Published: 31 May 2021

Publisher's Note: MDPI stays neutral with regard to jurisdictional claims in published maps and institutional affiliations.

Copyright: (c) 2021 by the authors. Licensee MDPI, Basel, Switzerland. This article is an open access article distributed under the terms and conditions of the Creative Commons Attribution (CC BY) license (https:// creativecommons.org/licenses/by/ $4.0 /)$.

\begin{abstract}
Recently, very rapid growth has been observed in the innovations and use of natural-fiberbased materials and composites for acoustic applications due to their environmentally friendly nature, low cost, and good acoustic absorption capability. However, there are still challenges for researchers to improve the mechanical and acoustic properties of natural fiber composites. In contrast, synthetic fiber-based composites have good mechanical properties and can be used in a wide range of structural and automotive applications. This review aims to provide a short overview of the different factors that affect the acoustic properties of natural-fiber-based materials and composites. The various factors that influence acoustic performance are fiber type, fineness, length, orientation, density, volume fraction in the composite, thickness, level of compression, and design. The details of various factors affecting the acoustic behavior of the fiber-based composites are described. Natural-fiber-based composites exhibit relatively good sound absorption capability due to their porous structure. Surface modification by alkali treatment can enhance the sound absorption performance. These materials can be used in buildings and interiors for efficient sound insulation.
\end{abstract}

Keywords: acoustic; natural fibers; composites; sound absorption coefficient; noise attenuation

\section{Introduction}

Recent advancement in controlling noise through sound absorption provides an opportunity to investigate various porous materials including fiber-based composites. Commercially available sound absorption materials are of three types, i.e., fibrous, granular, and cellular. Fibrous sound absorption materials are further divided into two categories, natural and synthetic, based on fiber origin. Interest in fiber-based composites is growing very rapidly due to their lightweight and high performance in several applications. Such composite materials receive great attention because of their wide range of applications in automotive, wind energy, sports, aerospace, and civil engineering applications. Fiber-based composite is the combination of fibers and matrix and the resultant material with improved mechanical properties compared with individual fibers and matrix [1,2]. Further, the natural-fiber-based composites are gaining importance because of their environmentally friendly nature. Natural-fiber-based composites have advantages such as high abrasive resistance, low emission of toxic fumes with heat, high specific strength, light weight, low cost, and eco-friendliness $[3,4]$. There are different types of sound absorbers, which include hollow resonant structures, porous structures, and composites, which also 
have a unique sound absorbing capability while interacting with different intensities and frequencies. In the beginning, asbestos-based materials were used as a sound absorber, but later, they were replaced with advanced alternatives. Asbestos was the material earlier used for soundproofing and sound insulation in 1800s in the US during the industrial revolution. Some properties of asbestos are non-flammability, non-corrosiveness, and good electrical insulation. It was one of the most widely used materials for soundproof applications in roofs, offices, houses, and roof ceilings in schools, etc. Asbestos consists of mineral fibers like anthophyllite, tremolite, crocidolite, amosite, actinolite, and chrysotile [5].

At the initial stage, there was a lack of understanding about the harmful effects of asbestos on animal and human health. Later, researchers found that asbestos is carcinogenic and hazardous to humans as well as animals. Since then, most countries around the world have banned the use of asbestos. Especially the European Union took very strict action and banned the use, import, and export of asbestos. Some industries use synthetic fibers as an alternative to asbestos fibers [6,7]. For synthetic fibers, often the starting materials used are cellulose or natural polymers. It was found that synthetic fibers are also hazardous for human health. Inhalation of synthetic fiber can cause lung injury, which leads to cancer [8-10].

Researchers are also working on the addition of granular materials to the fiber based composites, which significantly enhance flow resistivity and bulk density of the composite for increasing the chances of low-frequency sound absorption. However, the incorporation of such materials causes increased environmental pollution and $\mathrm{CO}_{2}$ emission, which cause global warming. Many sustainable natural fibers such as coir, banana, sugarcane, jute, and sisal are available for designing potential sound absorbers [11].

\section{Acoustic Properties of Fibrous Materials and Composites}

The sound absorption coefficient (SAC) can be calculated by measuring the total amount of sound energy absorbed by the materials. The range of SAC lies between 0 to 1 , in which 1 represents the highest absorption, while 0 shows no absorption at all. Absorption of low-frequency sound waves, e.g., $500 \mathrm{~Hz}$, is very difficult as compared to high-frequency sound waves. Propagation of sound waves through a medium without any absorption and loss of frequency is known as transmission [12,13]. The transmission coefficient $(t)$ is the fraction of incident energy that is not reflected or absorbed. The transmission loss can be defined as $10 \log (t) d B$. When the sound waves strike surfaces, some part is absorbed, while the rest is reflected $[14,15]$.

There are mainly two methods of measurement reported for sound absorption: the reverberation chamber method and the impedance tube method. The reverberation chamber method is widely used for a bigger sample size in order to determine the sound absorption coefficient [16]. The sample is mounted inside a sound insulated reverberation room/chamber. The walls, roof, floor, etc., are highly reflective. The sound in different frequencies is generated by a source and is allowed to propagate in all directions. The sample absorbs part of the sound energy, and the rest is reflected or diffused or even transmitted. This method involves a random incidence sound absorption, and the coefficient is termed the random incidence sound absorption coefficient.

In the case of a smaller sample size, the normal incidence impedance tube method is preferred $[17,18]$. The sound absorption performance of porous materials can be tested by the two-microphone impedance tube method, as shown in Figure 1. A two-microphone transfer function impedance tube (ISO-10534-2) in the frequency range of $100-2500 \mathrm{~Hz}$ is used during acoustic testing. It requires relatively small circular samples, either 29 or $100 \mathrm{~mm}$ in diameter according to the frequency range (500 to $6.4 \mathrm{kHz}$ or 50 to $500 \mathrm{~Hz}$, respectively). This method avoids the need to fabricate a large test sample with lateral dimensions several times the acoustic wavelength. The sound absorption coefficient is calculated for low as well as high frequency ranges. Average sound absorption coefficient values are reported. 


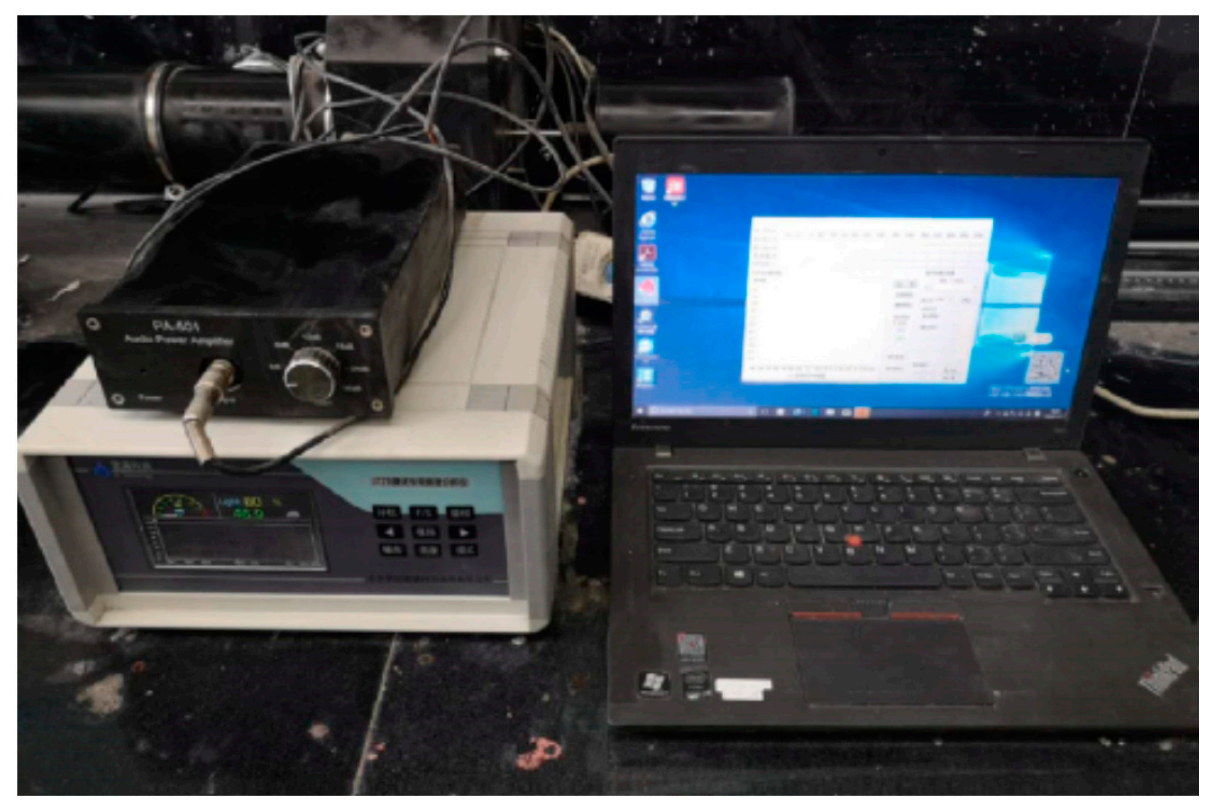

Figure 1. Impedance tube method for measurement of sound absorption [17].

\subsection{Classification of Sound in Terms of SAC}

The various classes of sound absorption as per ASTM C423-17 are given in Table 1.

Table 1. Classes of the sound absorption coefficient [13].

\begin{tabular}{cc}
\hline Range & SAC Class \\
\hline $0.90,0.95,1.00$ & $\mathrm{~A}$ \\
$0.80,0.85$ & $\mathrm{~B}$ \\
$0.60,0.65,0.70,0.75$ & $\mathrm{C}$ \\
$0.30,0.35,0.40,0.50,0.55$ & $\mathrm{D}$ \\
$0.15,0.20,0.25$ & $\mathrm{E}$ \\
$0.00,0.05,0.10$ & $\mathrm{~F}$ \\
\hline
\end{tabular}

Based on SAC, the sound absorption performance is classified into 6 classes, A, B, $\mathrm{C}, \mathrm{D}, \mathrm{E}$, and $\mathrm{F}$, as shown in Table 1. Category " $\mathrm{A}$ " is the most efficient class with the highest sound absorption coefficient, while category " $\mathrm{F}$ " denotes the minimum sound absorption coefficient.

\subsection{Sound-Absorbing Materials}

Sound absorbers are divided into resonators, porous absorbers, panel absorbers, and membranes. Some examples of porous absorbers are open-cell foams, mineral wool, and carpet. Porous absorbers allow sound and airwaves to pass inside the materials containing channels and cavities. As per the literature, sound absorbers are further categorized into fibrous, cellular, and granular types. Studies on sound absorption are focused on fibrous composite materials [19]. A comparative account of sound absorption in recycled polyurethane foam using various models and experiments is shown in Figure 2. 


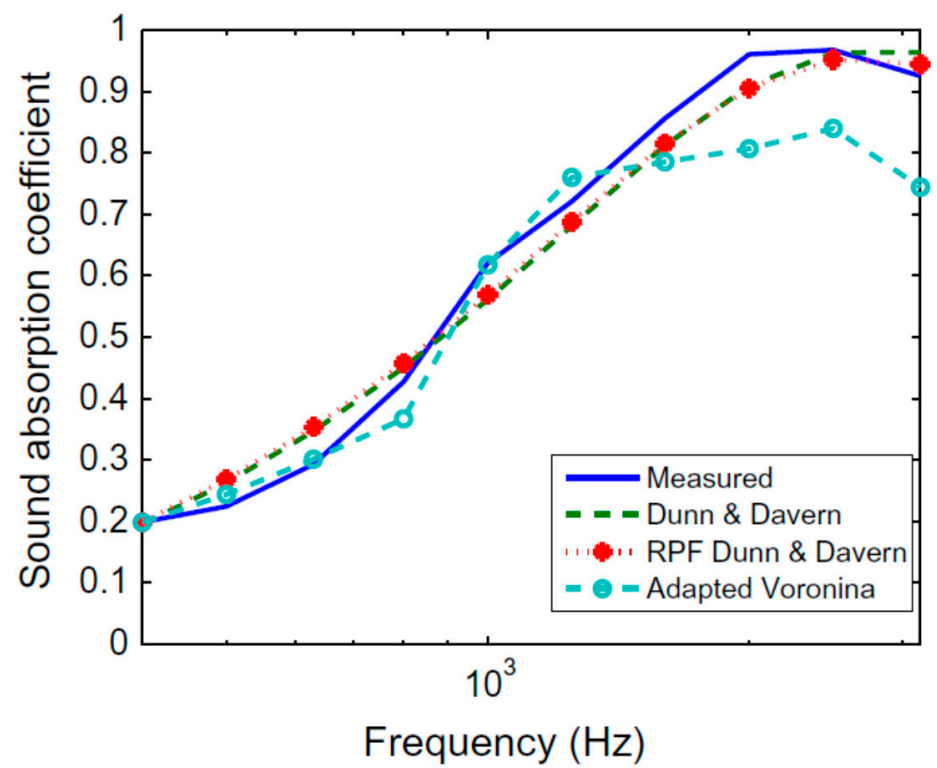

Figure 2. Sound absorption behavior based on various models [19].

The normal incidence sound absorption coefficient was measured for samples of $2 \mathrm{~cm}$ thickness using the impedance tube method. Experimental results were compared with two established theoretical models. The Dunn and Davern model is a semi-empirical model used to describe the acoustic behavior. This model determines the real and imaginary parts of the characteristic propagation constant and the characteristic wave impedance. It takes into account the air flow resistivity $\left(\mathrm{N} \mathrm{s} / \mathrm{m}^{4}\right)$ and frequency $(\mathrm{Hz})$ [19].

The Voronina model uses simple analytical functions that depend on the porosity of the material, the frequency, and the average pore diameter. A quantitative estimation of sound absorption in porous material is determined using structural characteristics. Using this model, the sound wave impedance and propagation constant are calculated from the porosity and average pore diameter for a material [19].

\subsection{Factors Affecting Acoustic Properties of Fibrous Sound-Absorbing Materials and Composites}

Materials with the ability to significantly absorb sound energy are known as sound absorbers. Sound absorption occurs while sound waves pass through a porous material, and a reduction in sound energy takes place due to friction with the pore walls and thermal exchange. There are certain factors like fiber size, temperature, porosity, and flow resistivity, density, thickness, compression, and design or placement that significantly affect the acoustic properties of fibrous materials and their composites.

\subsubsection{Effect of Different Fiber Types}

Researchers investigated the acoustic properties of lignocellulosic fibers based composites. Three types of thermoplastic binders, e.g., zein, polylactic acid, and polypropylene, were used. Additionally, two types of thermoset binders, epoxy and unsaturated polyester (UP), were used for impregnation. Further, five types of fibers, betel nuts, oil palm, rice straw, sisal, and luffa fibers, were used as reinforcement. The results revealed that physically and chemically treated fibers show a higher sound absorption coefficient than untreated fibers. As fiber volume fraction is increased, the sound absorption coefficient increases as well. Among all samples, the polypropylene/rice straw composite showed the highest sound absorption coefficient. Surface modification causes further enhancement of the interfacial adhesion, which significantly enhances mechanical properties. Mihai Bratu et al. investigated the acoustic behavior of different composites based on waste fibers and other wastes. Formaldehyde was used as a matrix along with steelworks slag, fiberglass waste, wood waste, and waste ash from burning shells of plants as filler. The best 
result was obtained for wood waste and glass fiber waste. Therefore, it can be used as an absorbing panel in industries and automotive, etc. [20].

Yang and $\mathrm{Li}$ investigated the acoustic behavior of natural-fiber-based composites. They used jute, flax, and ramie fibers as a reinforcement and Epoxy resin as a matrix. It was found that, at a frequency range of $256-2000 \mathrm{~Hz}$, ramie, jute, flax, glass, and carbon fibers show SAC of $0.6,0.65,0.65,0.35$, and 0.45 respectively. The jute fiber-based composite materials show a sound absorption coefficient of 0.9 at $10,000 \mathrm{~Hz}$ frequency, as shown in Figure 3 [21].

Elammaran Jayamani et al. investigated the acoustic behavior of lignocellulosic agricultural fibers and their composites. Kenaf and rice straws (RS) were used along with urea-formaldehyde (UF) and polypropylene (PP) as a matrix. It was found that, by increasing the frequency of incident sound waves, the absorption coefficient also increases. Kenaf-fiber-based urea-formaldehyde composites with a thickness of $1.8 \mathrm{~cm}$ showed a higher sound absorption coefficient as compared to PP-based samples of similar thickness. It is stated that polymer composites have an average SAC ranging between 0.008-0.065 [22] Zhang et al. investigated the sound absorption of natural fibers and sandwich composites structures. Flax fabric was used as reinforcement and epoxy as the matrix. It was found that flax-fiber-based composites show superior acoustic absorption compared to glassfabric-based composites, as shown in Figure 4. Flax fiber composites show relatively better sound absorption at a wider frequency range. It is due to their fibrous microstructure and multi-scale micro-morphology [23].
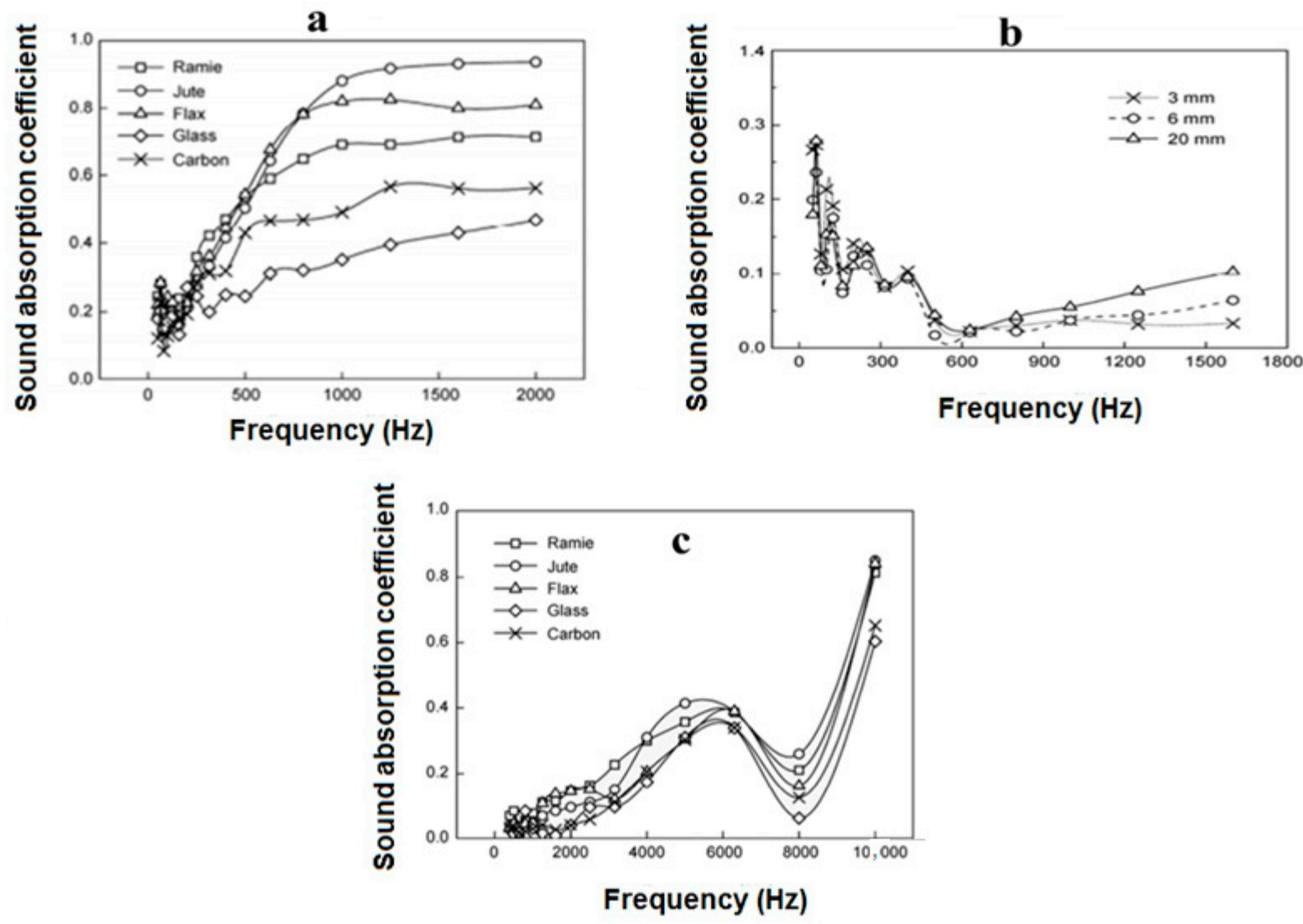

Figure 3. SAC of (a) different fibers, (b) epoxy resin, (c) fiber composites [21]. 


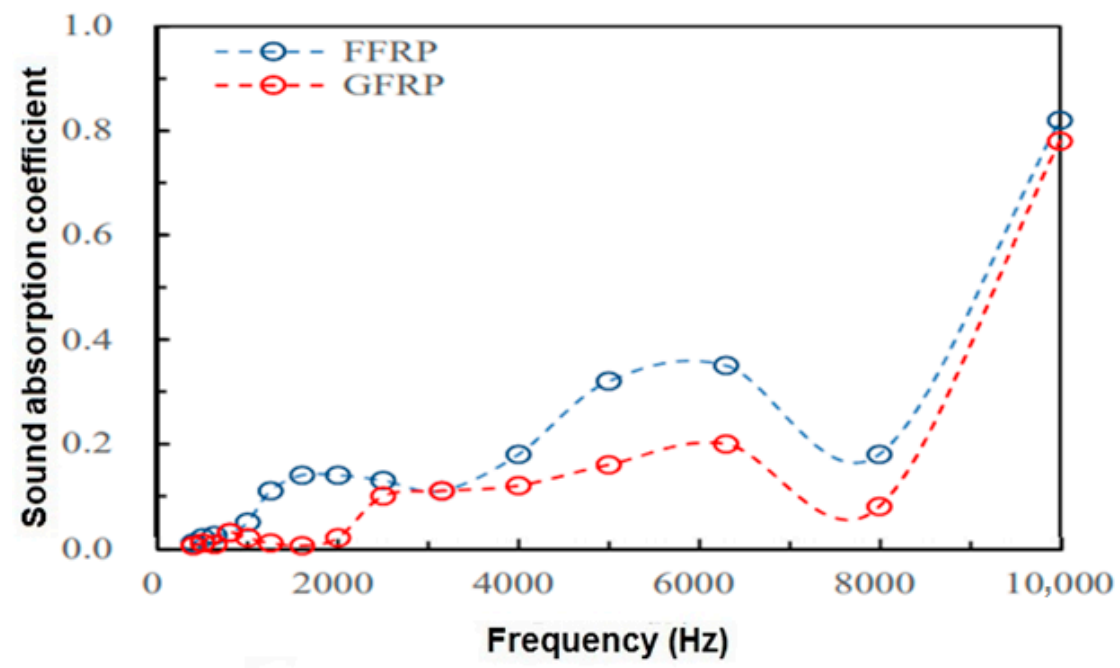

Figure 4. SAC of flax-fiber-based composite and glass-fiber-based composite [23].

Zhang et al. evaluated the acoustic properties of various natural-fiber-based composites using the acoustic impedance tube. It was found that jute-fiber-based composites showed maximum sound absorption performance for a wide range of frequencies, as shown in Figure 5 [24].

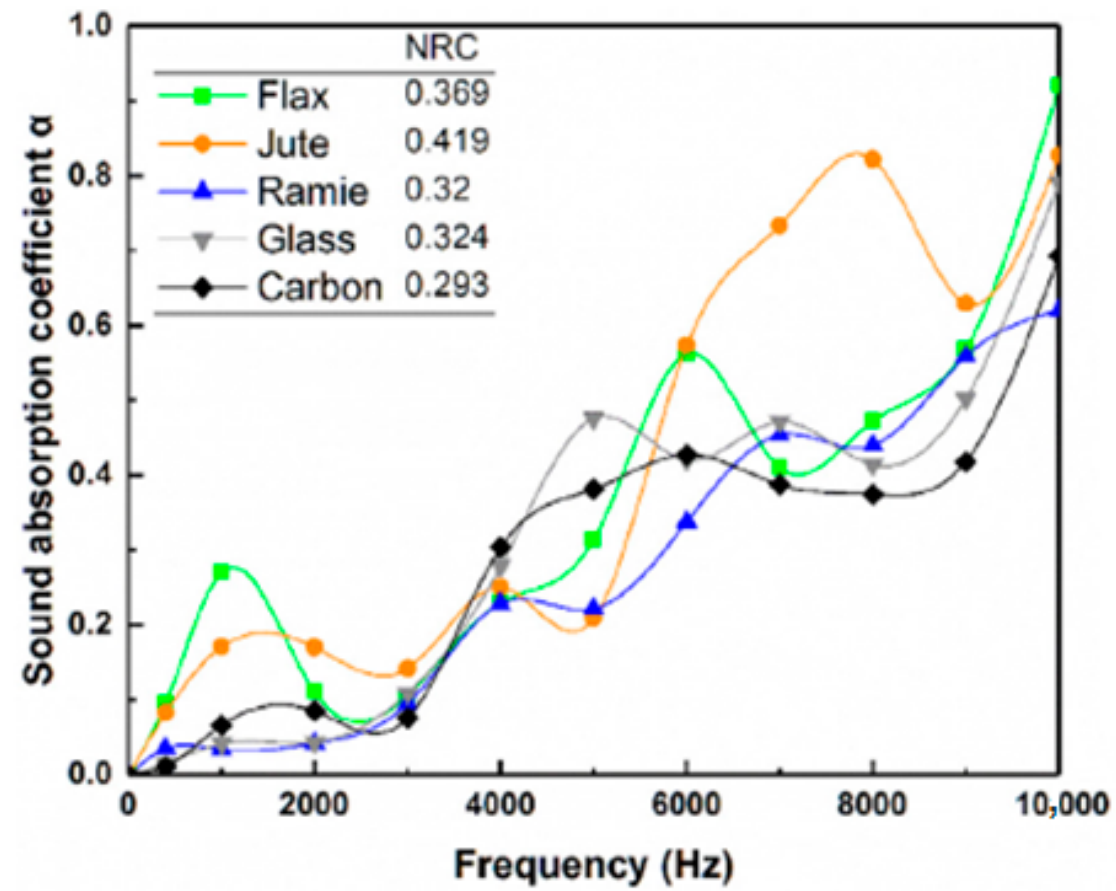

Figure 5. The sound absorption coefficient of natural-fiber-based composites of thickness $1.8 \mathrm{~cm} \mathrm{[25].}$

Maderuelo-Sanz et al. reported on the sound absorption performance of composites produced from waste tires. The sound absorption coefficient of panels having $2.0 \mathrm{~cm}$ thickness is shown in Figure 6 [26]. 


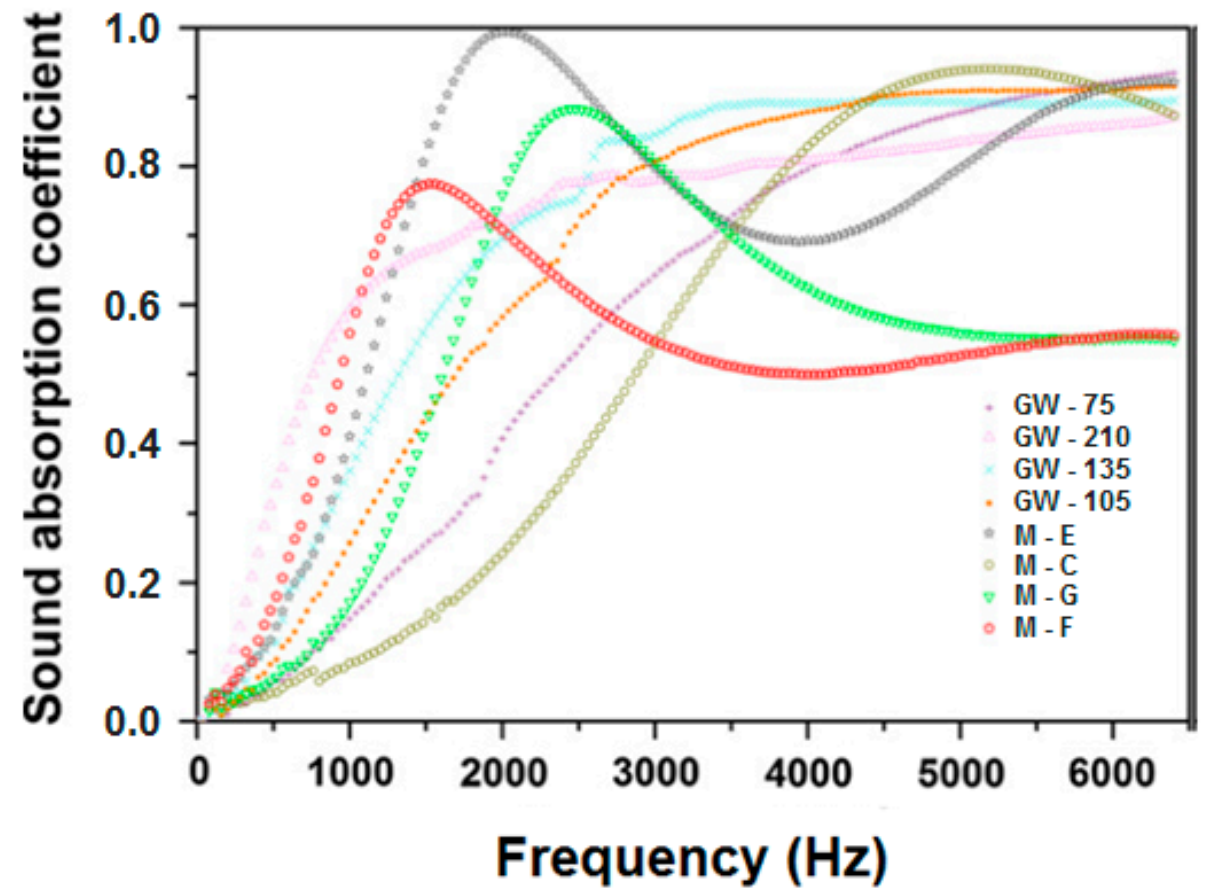

Figure 6. Absorption coefficient of panels made from tire waste [26].

The real and imaginary part of acoustic impedance for panels are shown in Figure 7. The real part is the resistance associated with energy losses, and the imaginary part is the reactance, associated with phase changes [26,27].
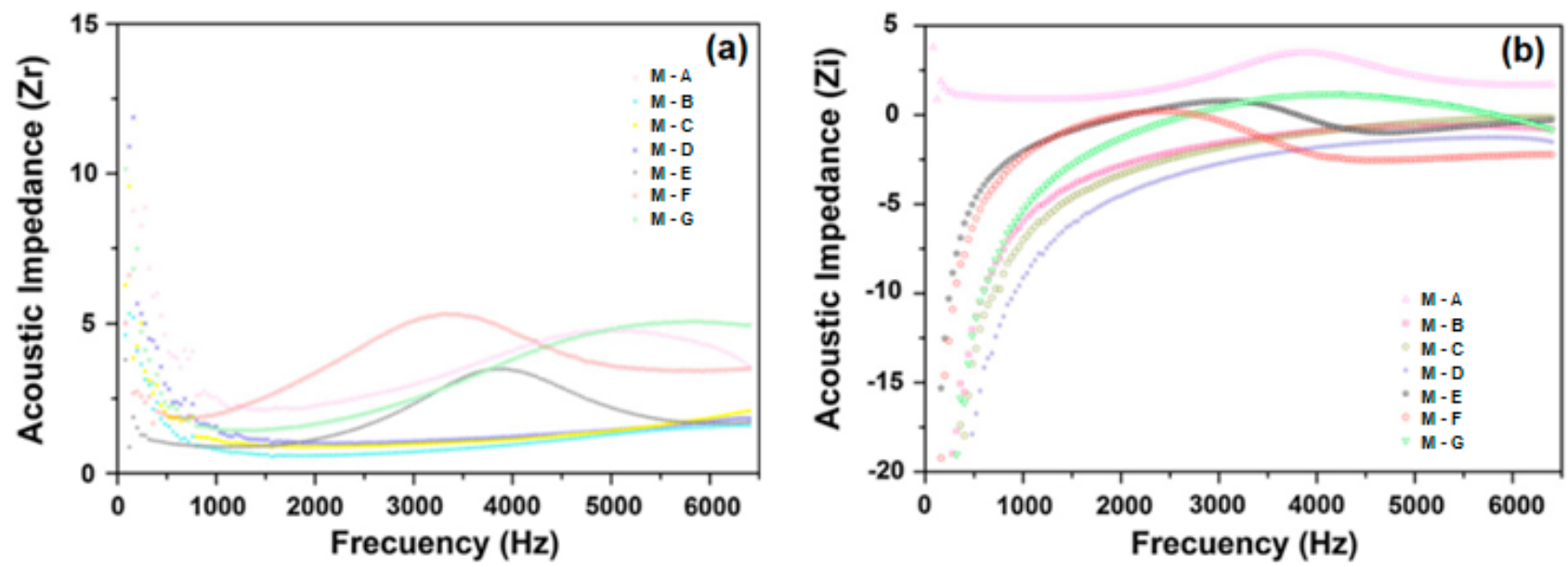

Figure 7. (a) Real and (b) imaginary part of acoustic impedance for sound absorbers made from tire wastes [26].

Prabhu et al. investigated the sound absorption performance of sisal- and tea-fiberwaste-based composites. As shown in Figure 8, tea-fiber-based composite samples with thickness $1.5 \mathrm{~cm}$ exhibited better sound absorption coefficients as compared to other fibers [28]. 


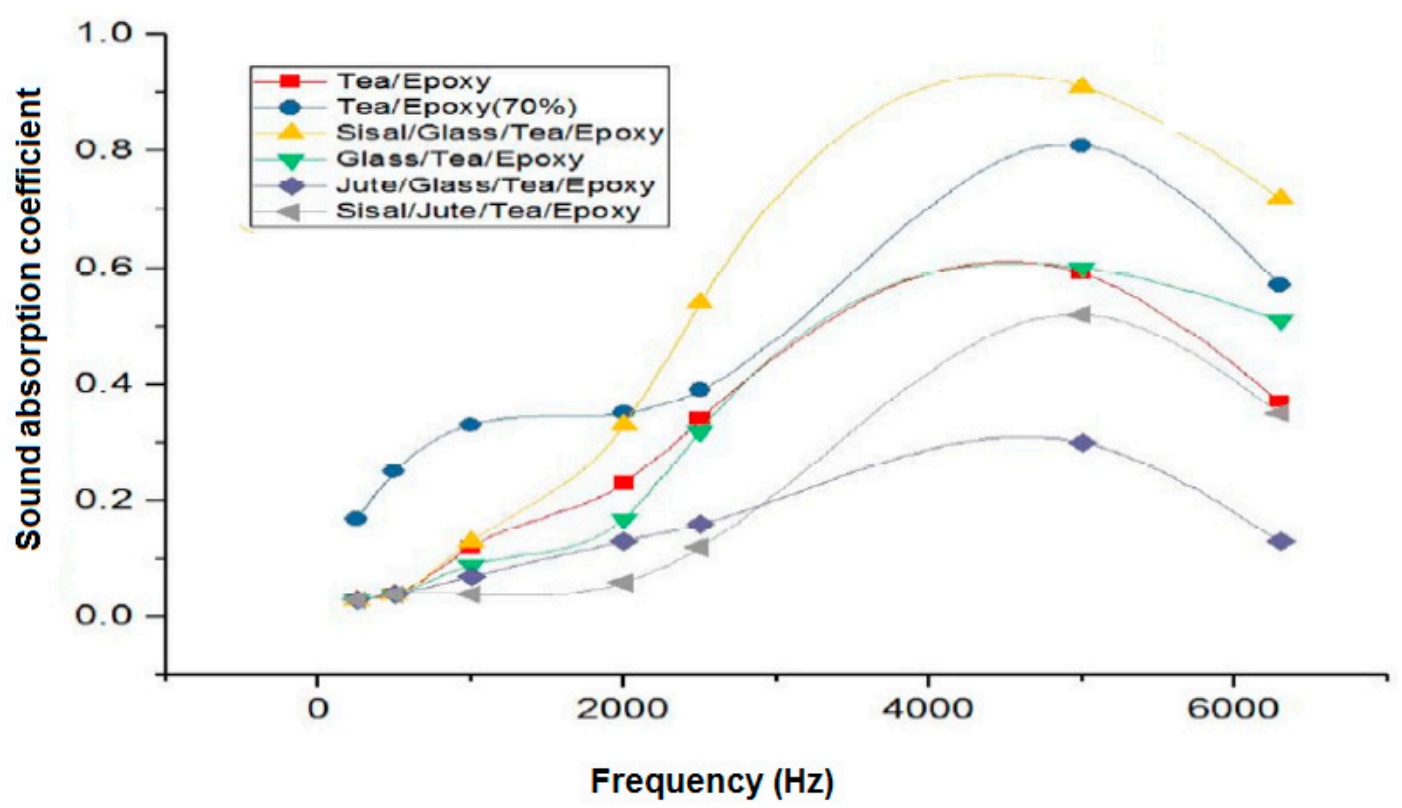

Figure 8. Sound absorption of composites with tea fibers [28].

Tiuc et al. investigated the acoustic properties of textile-waste-based rigid polyurethane closed-cell foam. Textile waste in the portion of $10-50 \%$ was used in the composites. As shown in Figure 9, better sound insulation was achieved as compared to pure polyurethane material with a thickness of $2 \mathrm{~cm}$ [29].

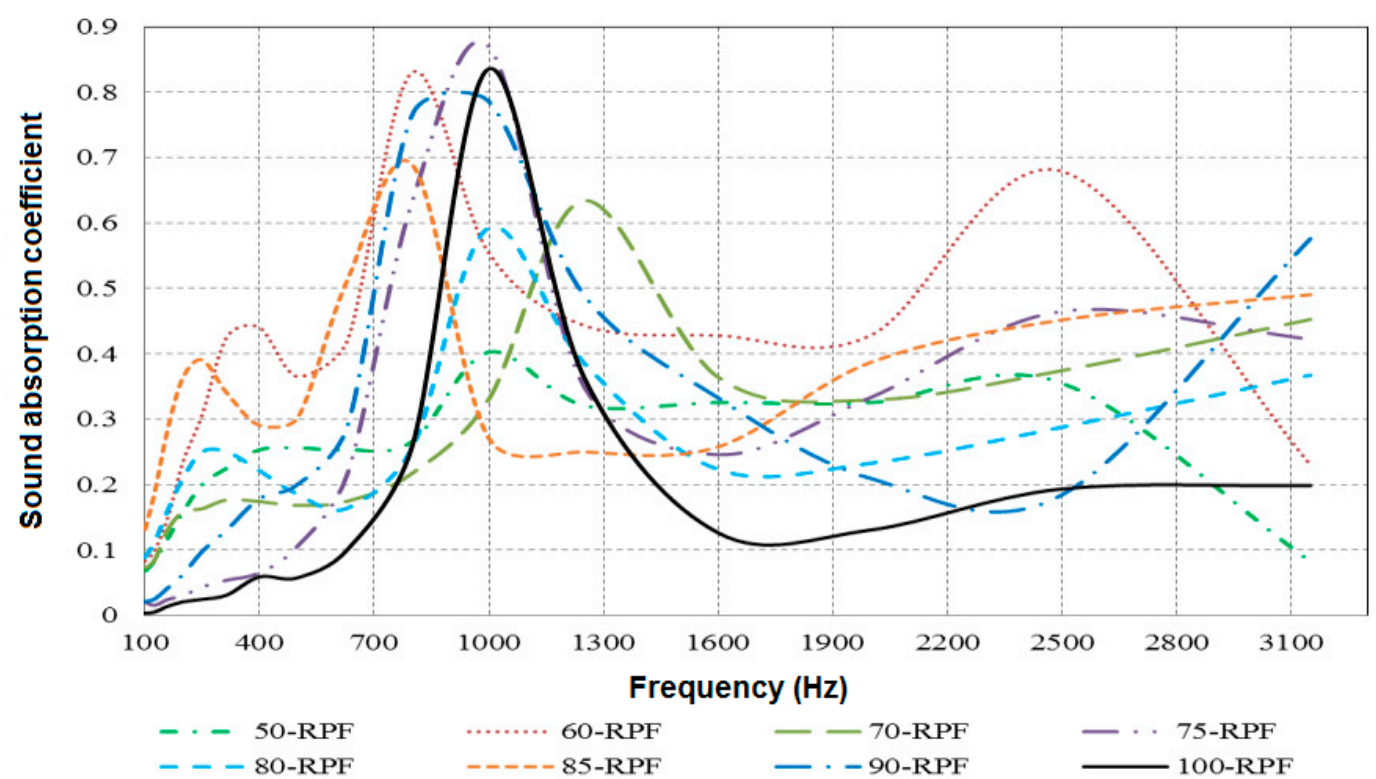

Figure 9. The sound absorption coefficient of PU foam is based on different proportions of textile waste [29].

Elammaran Jayamani et al. investigated the sound absorption coefficient of naturalfiber-based epoxy composites. They used sugarcane bagasse, kenaf, and coconut fibers in epoxy composites with a thickness of $1.8 \mathrm{~cm}$. It was found that at the $500-2500 \mathrm{~Hz}$ frequency range, sugarcane fiber composites provide better sound absorption, while coconut fiber composites also have good sound absorption at 2500-4000 and 5500-6000 Hz. Due to higher density, sugarcane-fiber-based composite was found to be a better sound absorber at relatively lower frequencies. It was also found that coconut-, kenaf-, and sugarcane-fiberbased composites have sound absorption coefficients of $0.086,0.086$, and 0.085 , respectively. 
Chen et al. also reported on the acoustic properties of ramie-fiber-based composites with a thickness of $2.0 \mathrm{~cm}$ [30].

\subsubsection{Effect of Fiber Size}

A change in fiber size may be a change in length or diameter. Fiber size is considered one of the major factors that affect acoustic properties. Lee et al. investigated the effect of fiber diameter on the acoustic properties of composites. They used polyester with different fiber fineness, e.g., 1.25, 2, and 7 deniers. Non-woven samples with a thickness of $2.5 \mathrm{~cm}$ were developed from these fibers by using low melting polyester for binding purposes. It was found that by reducing fiber diameter, the sound absorption coefficient increases. It is because airflow resistance increases with smaller fiber diameter [31].

Koizumi et al. concluded that by decreasing fiber diameter, the sound absorption coefficient increases, as shown in Figure 10. It was described that fiber denier ranging from 1.5 deniers to 6 deniers results in better sound absorption than coarser denier. Further, it was concluded that by using micro-denier fibers, a dramatic enhancement in sound absorption coefficient can be achieved [32].

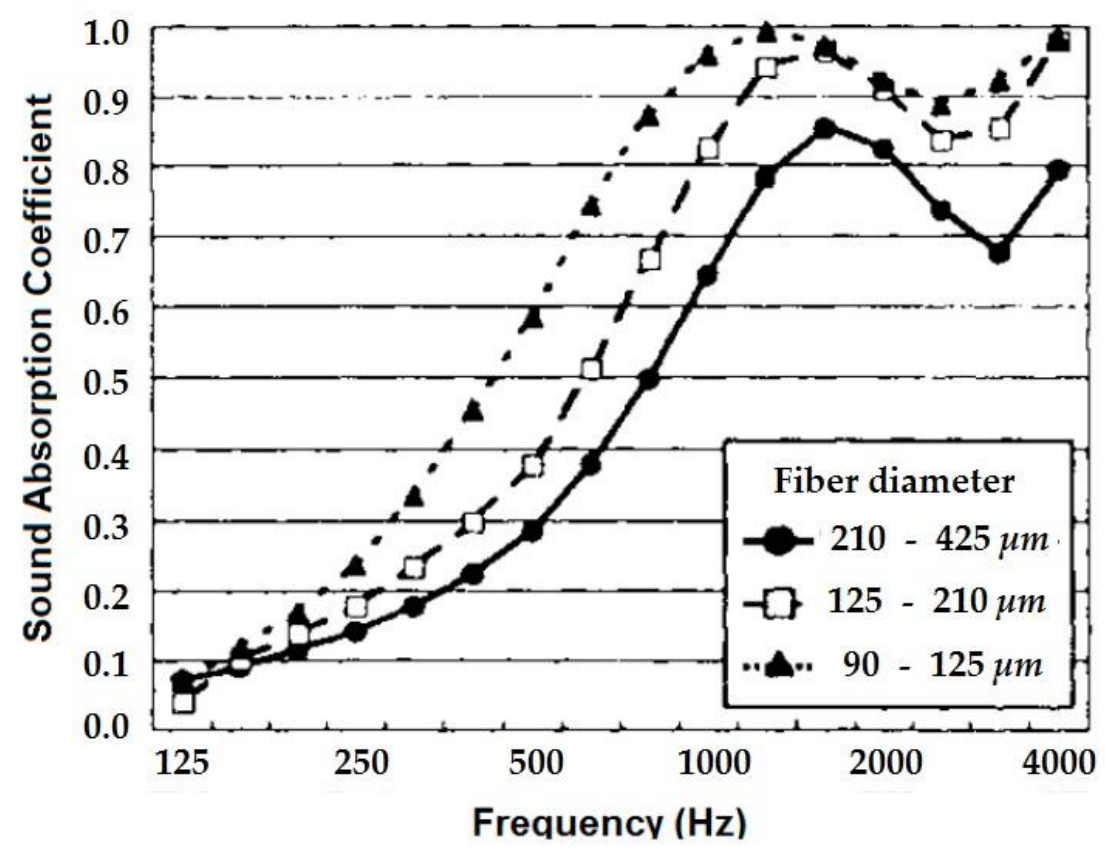

Figure 10. SAC comparison of different fiber diameters [32].

Ren et al. described that for achieving efficient SAC with the same volume density, finer fibers are preferred as compared to coarser fibers. More fibers per unit area result in a more tortuous path, which results in a higher sound absorption coefficient [33].

Bakri et al. investigated the SAC of banana-fiber-based epoxy composites. The results revealed that, by decreasing fiber diameter, flow resistivity increases, which causes an increase in the SAC as shown in Figure 11 [34]. Hasina Mamtaz et al. investigated the acoustic behavior of various other natural-fiber-based composites with a thickness of $1.8 \mathrm{~cm}$. They also found that fiber diameter is an important parameter for enhancing sound absorption. By decreasing fiber diameter, SAC increases [35]. 


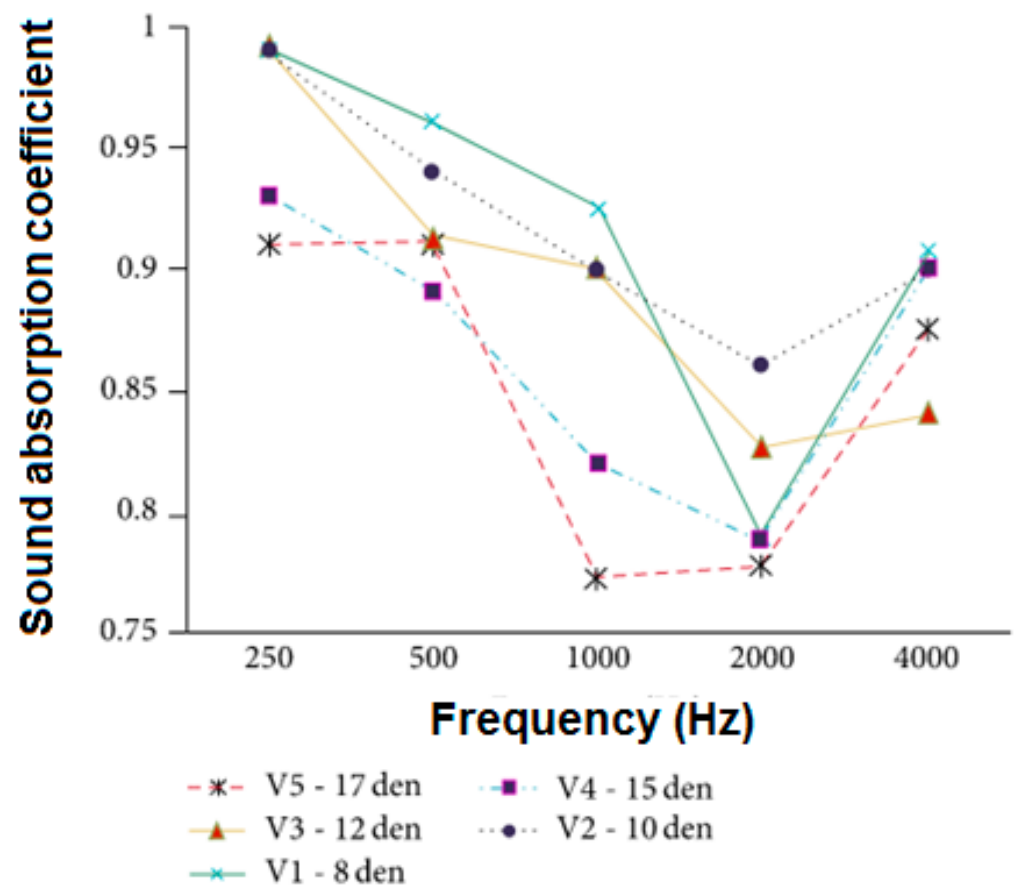

Figure 11. Effect of fiber diameter on SAC of composites [34].

Luu et al. researched the acoustic properties of polydisperse fiber networks. They used effective fiber diameter for modeling. During reconstruction, they considered two types of polydisperse fiber matrix and bi-dispursed fiber matrix. Results reveal that fiber diameter has a significant effect on the sound absorption coefficient. A significant increase in the sound absorption coefficient has been observed by decreasing fiber diameter [36].

Xiang et al. investigated the acoustic properties of kapok fibers. The results revealed that long fibers have slightly higher SAC than short fibers. Further, the random orientation of fibers shows higher SAC than oriented fibers [37]. V. Arumugam et al. conducted a study on the effect of fiber orientation on acoustic properties of the glass epoxy laminates. Different stacking sequence was used to investigate its mechanical properties. A significant effect on acoustic behavior has been observed by changing the orientation, which also changes overall porosity [38].

Chen et al. studied the morphology and properties of ramie-fiber-based PLLA composites. They used fibers of different lengths. A fiber volume fraction of 30:70 ramie/PLLA was used for composite manufacturing. The acoustic properties of the resultant sample were measured through the standing wave tube method. Results revealed that when sound hits the surface of the composite, the non-vertical angle fiber with incident wave absorbs some part of the sound wave. Moreover, the composite with shorter ramie fiber was found to be a better sound absorber [30].

\subsubsection{Effect of Fiber Fraction}

Jiang et al. studied and reported the sound absorption performance of seven-hole hollow polyester fibers (SHPF)-based composite samples with a thickness of $1.5 \mathrm{~cm}$ [39]. The influence of increasing fiber fraction on the sound absorption coefficient is shown in Figure 12. With increasing fraction of hollow fibers, the sound absorption performance is observed to improve. 


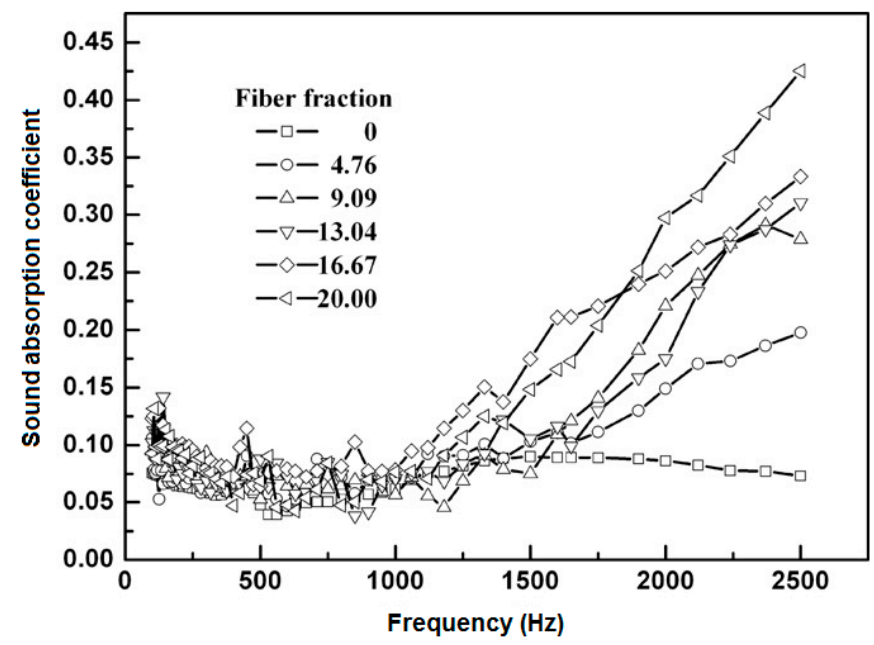

Figure 12. Effect of hollow fiber fraction on the sound absorption performance of composites [39].

Sheng Jiang investigated the sound absorption coefficient of seven-hole polyesterbased chlorinated polyethylene composite. It was found that the SAC of untreated polyethylene was 0.2 at $100-2500 \mathrm{~Hz}$ frequency range. By increasing reinforcement content, remarkable improvement has been observed in SAC. At $20 \mathrm{wt} . \%$ fiber content, SAC is found to be 0.42 for sample thickness of $2 \mathrm{~cm}$. As the thickness of the composites increases, the SAC also increases. It was found that by increasing reinforcement content, SAC is significantly improved, as shown in Figure 13 [39].

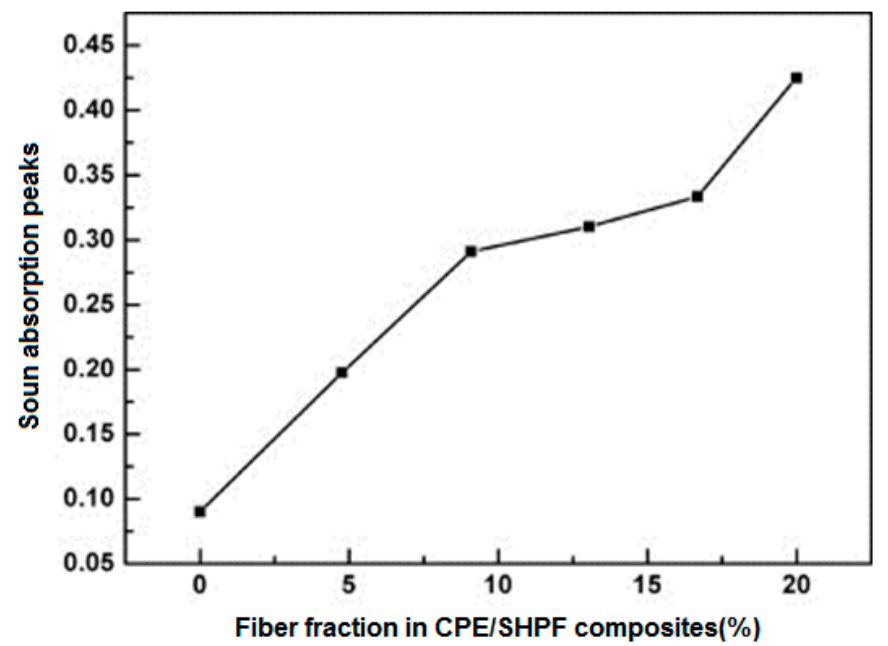

Figure 13. Effect of fiber content on CPE/SHPE composite [39].

Abdul Hakim Abdullah et al. investigated the sound absorption of natural-fiberbased composites. The study was mainly conducted to find out the SAC of banana fibers, sugarcane bagasse fibers, and their hybrid composites with thickness of $1 \mathrm{~cm}$. Polyester binders were used as a matrix. It was found that the sound absorption coefficient of sugarcane fiber is 0.6338 and of banana fiber is 0.6635 , and by the combination, it reaches up to 0.733 at $2325 \mathrm{~Hz}$ frequency. For $20 \mathrm{wt} \%$ fiber volume fraction, banana fiber has 0.586 , sugarcane has 0.71 , and a combination of both fibers has $0.73 \mathrm{SAC}$ at $2500 \mathrm{~Hz}$ frequency. It was also established that by increasing fiber volume fraction, sound absorption increases [40].

Elammaran Jayammani et al. investigated the acoustic properties of epoxy-based banana-fiber composites. It was found that by increasing frequency, the sound absorption coefficient increases. By increasing fiber content, sound absorption also increases. It was also found that alkali-treated fiber composites have a higher sound absorption coefficient 
as compared to untreated fiber composites. It is because materials with lower molecular weight were removed, which reduces sound reflection and increases absorption [41].

An inspection of the effect of fiber loading on the sound absorption property of flax fiber-based composites (FFRC) was conducted and presented in Figure 14 [42].

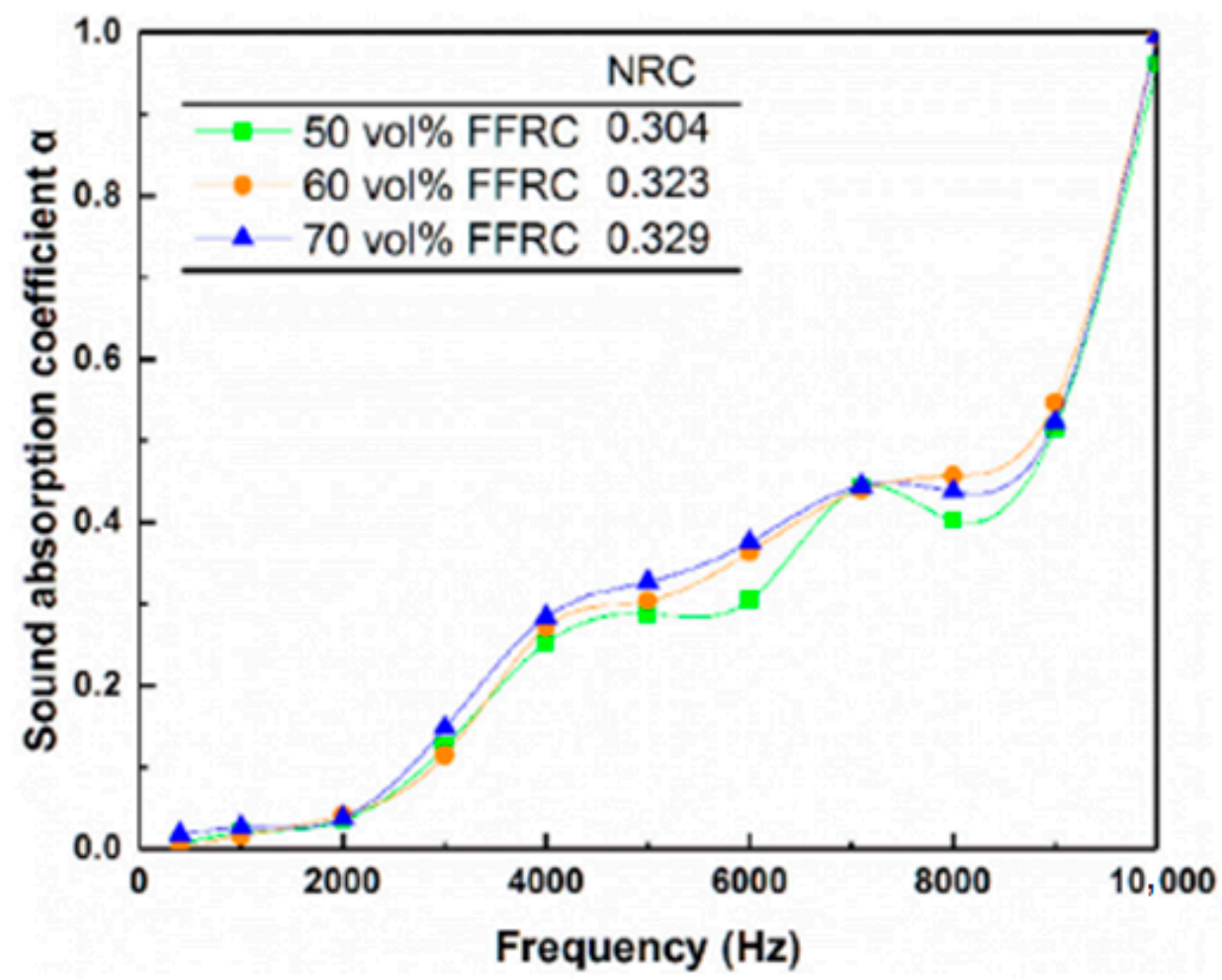

Figure 14. Effect of flax fiber content on SAC [42].

Reixach et al. also investigated the acoustic properties of natural-fiber-based composites. The effect of fiber content on the transmission losses for sample thickness $1.1 \mathrm{~cm}$ are shown in Figures 15 and 16. The effect of fiber treatment on the sound absorption performance was also reported [43].

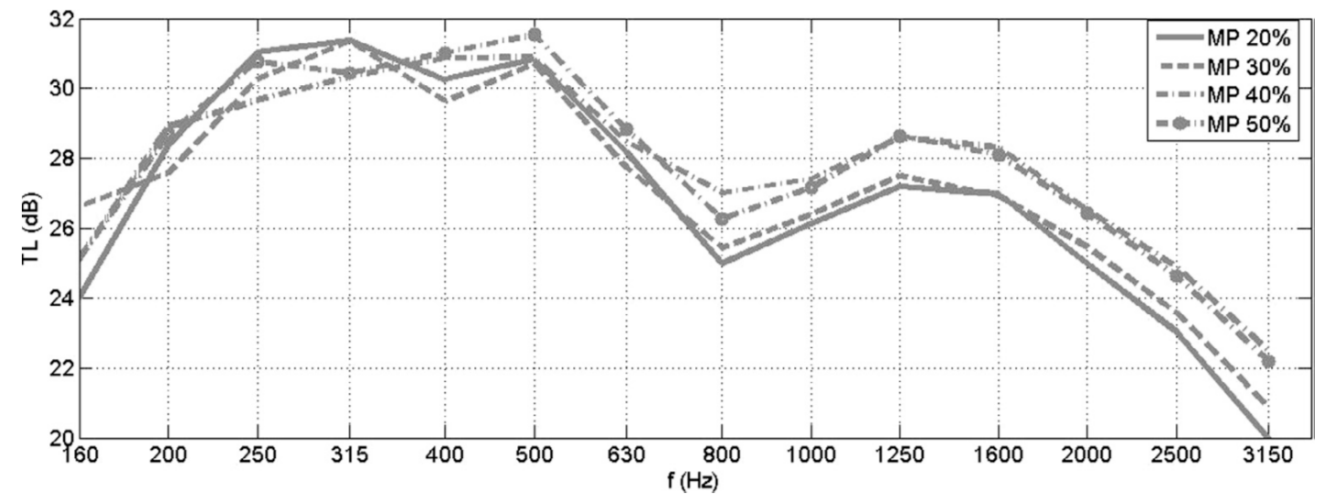

Figure 15. Transmission loss (TL) for the 20-50\% polypropylene based composites [43]. 


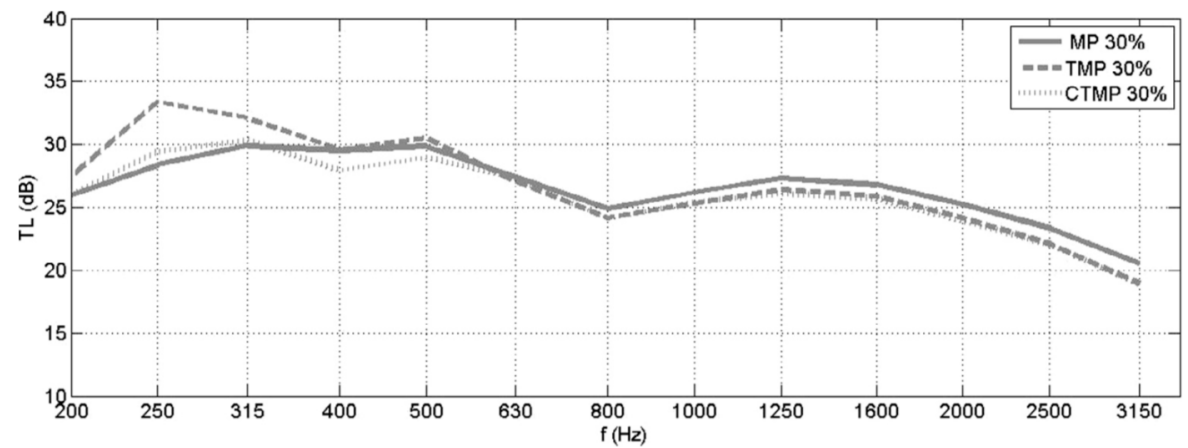

Figure 16. Transmission loss (TL) for the $30 \%$ polypropylene based composites [43].

\subsubsection{Effect of Fiber Treatment}

Elammaram Jayamani et al. investigated and found that alkali-treated and heat-treated fiber-based composites have a relatively higher sound absorption coefficient than untreated composites [44]. They further investigated the effect of alkali treatment on the sound absorption coefficient of other natural-fiber-based polymer composites. Sisal, rice straws, betel nuts, luffa, and fruit bunch were used as reinforcement. Further, polymers epoxy, unsaturated polyester (thermoset), and three types of thermoplastic polymers zein, polypropylene, and polylactic acid were used as a matrix. Fibers were treated with $5 \mathrm{wt} \%$ alkali solution. It was found that the sound absorption coefficient of natural fibers is relatively good due to the presence of inter-fiber microvoids in the fiber structure. Alkali-treated fiber-based composites in all cases exhibited a higher sound absorption coefficient compared to untreated fiber-based composites. The alkali treatment changes the composition of fibers, which causes the relative motion between polymers and fibers [45-54]. The influence of alkali-treated betelnut fiber on SAC for $1 \mathrm{~cm}$ thick samples is shown in Figure 17.

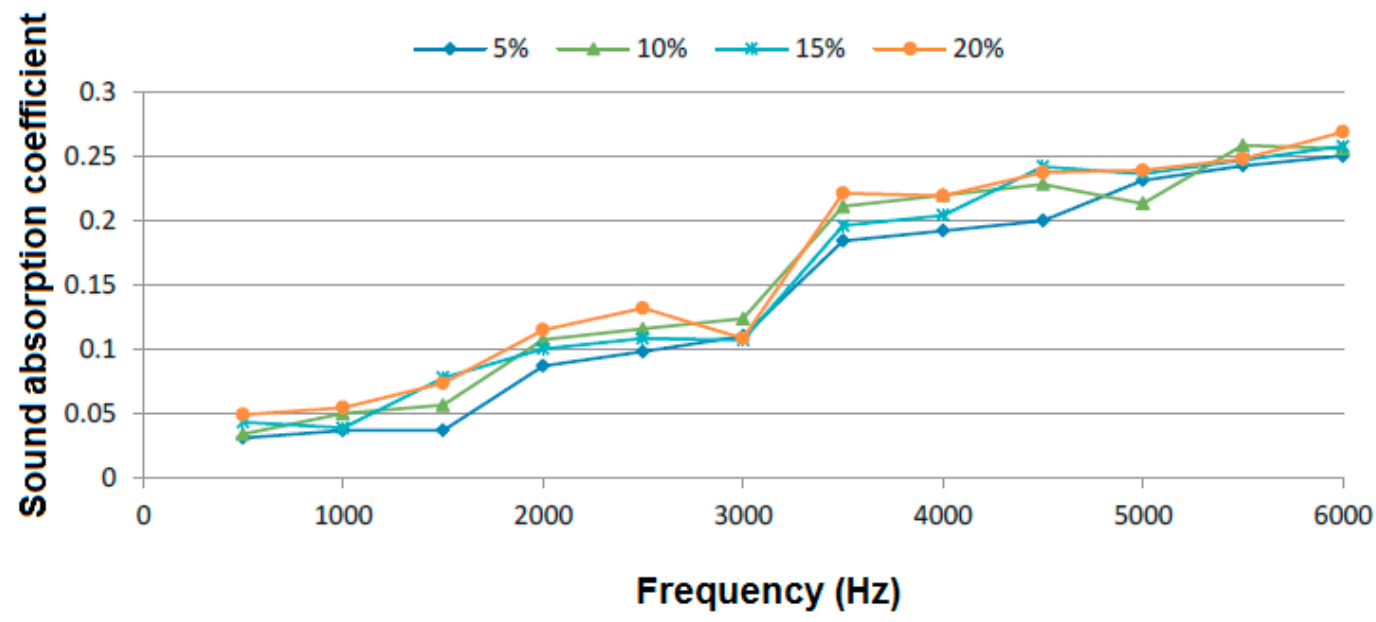

Figure 17. Influence of betelnut fiber content on sound absorption coefficients of composites [54].

S. Fatima and A.R. Mohanty reported a study on the effect of fiber treatment on the acoustic properties and fire-retardant properties of jute fiber and its composites. Before conducting testing, some physical properties of the fibers were measured, e.g., tortuosity, porosity, and flow resistivity. For measuring the sound absorption coefficient, cylindrical shape commercial-grade treated (TD4) and untreated (TD5) jute were used. Two-microphone impedance tubes were used for measuring the sound absorption coefficient. Results reveal that treatment removes the impurities and the surface becomes rougher, which significantly enhances mechanical properties and acoustic absorption of the fiber-based composites [55]. 


\subsubsection{Effect of Sample Thickness}

The sample thickness is one of the most important characteristics that influence the sound absorption performance. Change of thickness changes several other parameters, including density and porosity. Coates et al. studied the effect of thickness on the acoustic behavior of porous materials. Effective absorption of sound is achieved at $1 / 10$ th of the wavelength of incident sound waves in their measurements [54]. Hirabayashi et al. described that at resonance frequency, peak absorption can occur at one-quarter of the incident sound wave. It is clear that there is a significant relationship between SAC and thickness of the materials at high, medium, as well as low frequencies [56]. The material thickness should be a quarter of the wave length of the sound wave to be an effective absorber. This is applicable to all measurements involving the impedance tube method where hard backing is used.

Ibrahim et al. also described that increasing thickness causes an increase in SAC. At relatively higher frequencies, sound absorption increases nonlinearly [57]. The influence of thickness on SAC is shown in Figures 18-20 from the reported literature [58].

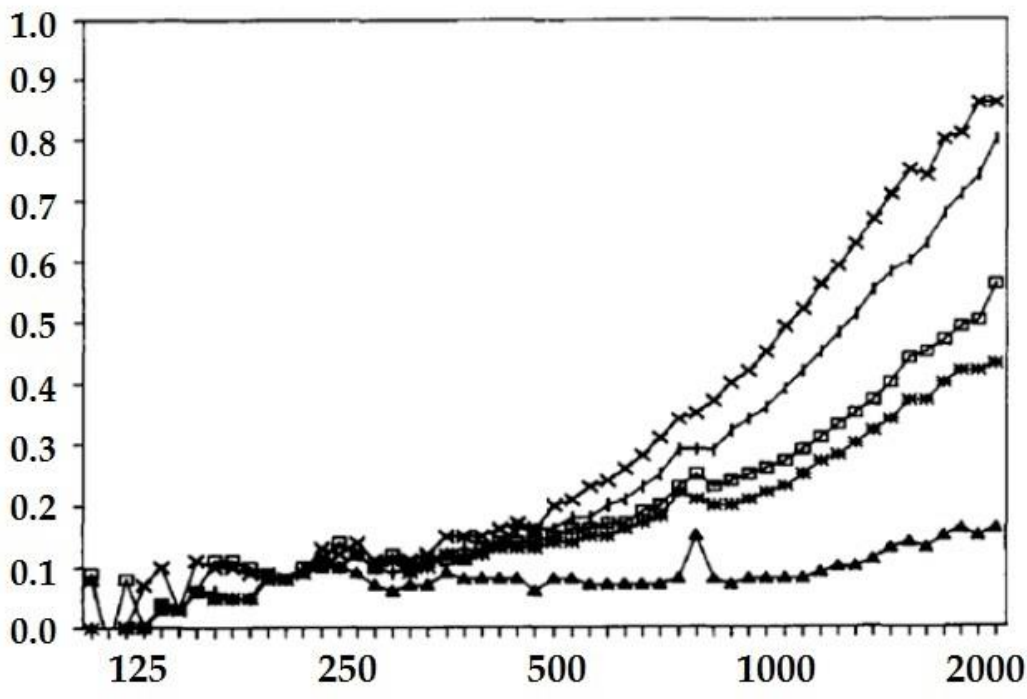

$75 \mathrm{~kg} / \mathrm{m}^{3}, 20,000 \mathrm{Rayl} / \mathrm{m}$

$+98 \mathrm{~kg} / \mathrm{m}^{3}, 16,000 \mathrm{Rayl} / \mathrm{m}$

$\rightleftarrows 47 \mathrm{~kg} / \mathrm{m}^{3}, 8000 \mathrm{Rayl} / \mathrm{m}$

* $38 \mathrm{~kg} / \mathrm{m}^{3}, 3300 \mathrm{Rayl} / \mathrm{m}$

$10 \mathrm{~kg} / \mathrm{m}^{3}, 720 \mathrm{Rayl} / \mathrm{m}$

Frequency $(\mathrm{Hz})$

Figure 18. SAC of $2.5 \mathrm{~cm}$ thick wool samples [57]

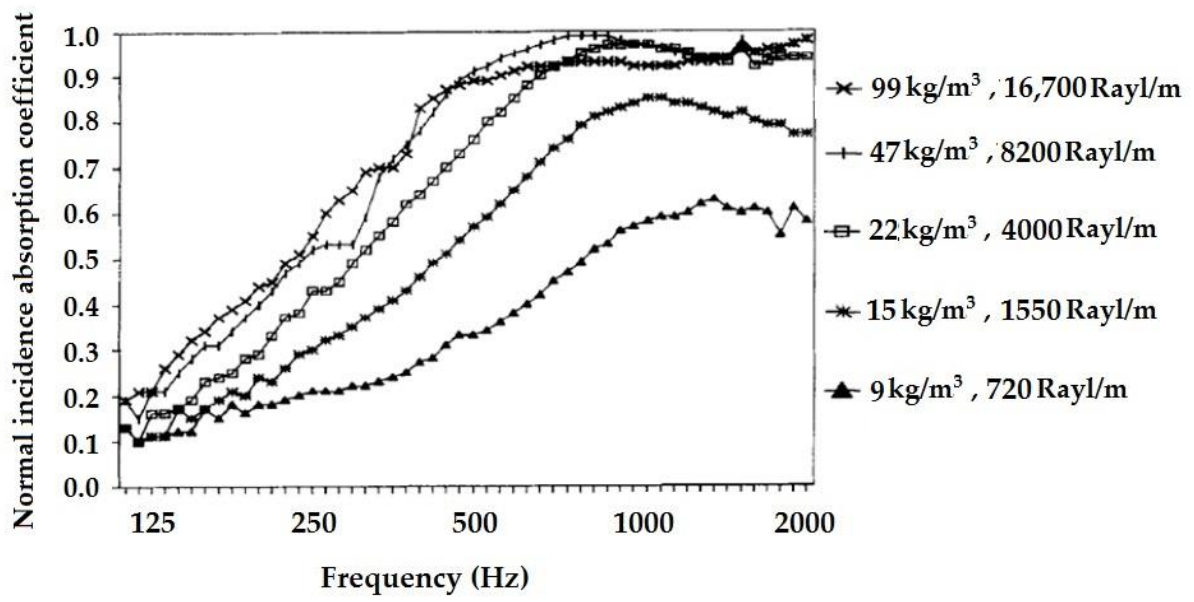

Figure 19. SAC of $1 \mathrm{~cm}$ thick wool samples [57]. 


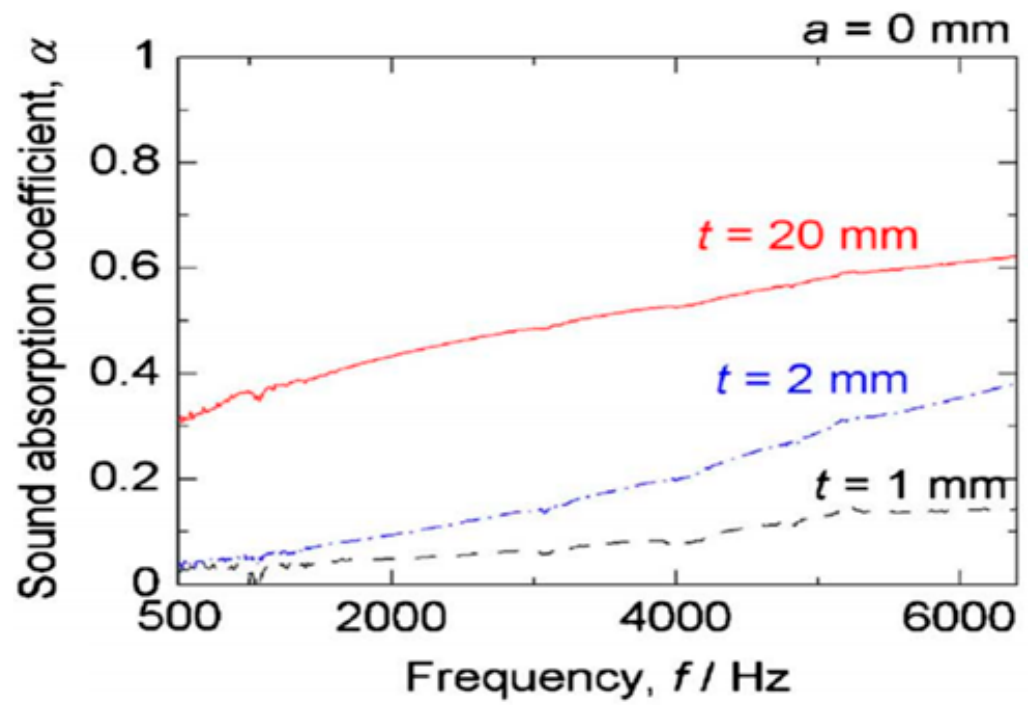

Figure 20. Effect of thickness on SAC [58].

Jiang et al. reported that by increasing the thickness of seven-hole polyester fiber and chlorinated polyethylene composite, a significant improvement in sound absorption coefficient was observed. They investigated the acoustic properties of a seven-hole hollow-polyester-fiber-based chlorinated polyethylene (CPE) composite. Polyester fiber with 10Dtex fineness and $60 \mathrm{~mm}$ length was used in the study. During composite manufacturing, a fiber volume fraction of 65:35 and a reinforcement/matrix was used with three different thickness levels of 1,2 , and $3 \mathrm{~mm}$. Test results conclude that by increasing the thickness of the sample, the sound absorption coefficient will also be increased, as shown in Figure 21 [59].

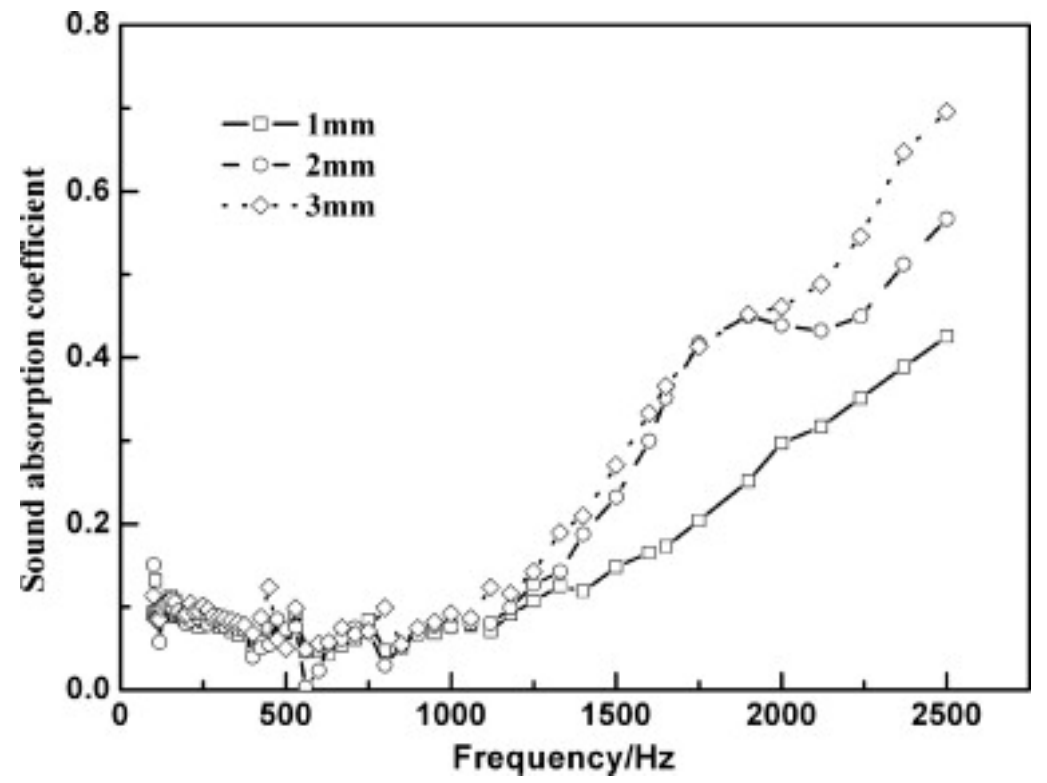

Figure 21. Effect of thickness on SAC [59].

The effect of thickness on the sound absorption coefficient is shown in Figure 22. A higher sound absorption coefficient was obtained by increasing the thickness of composites. 


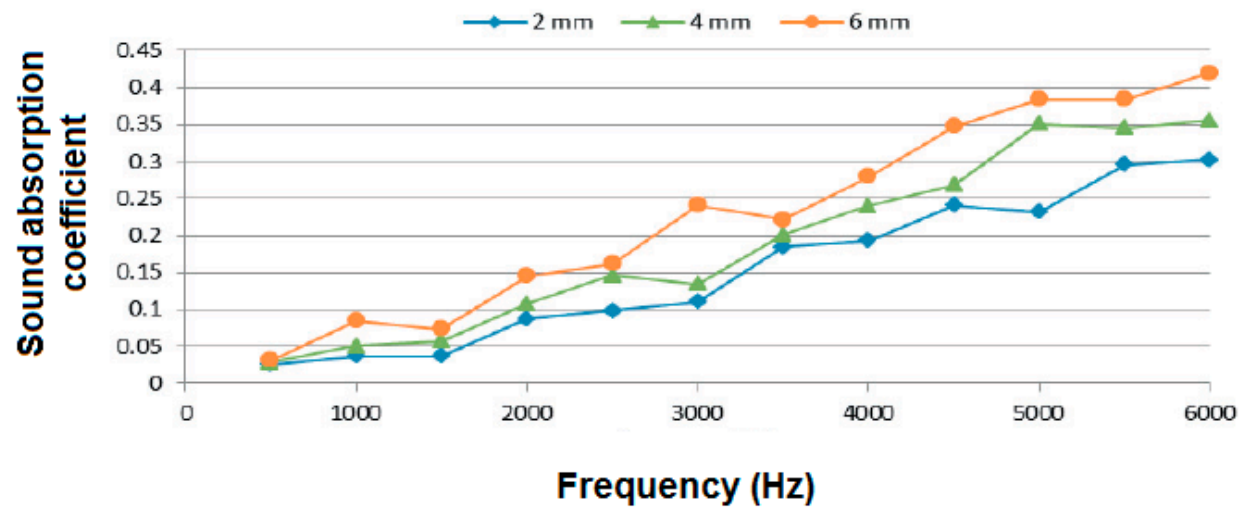

Figure 22. Influence of thickness of composites on sound absorption coefficients [59].

Hasina Mamtaz et al. investigated the sound absorption coefficient of fibro-granular epoxy composites. Coconut/coir fiber was used along with rice husk grain as a granular filler material. The results shown in Figure 23 reveal that by increasing thickness, the SAC of composites also increases [35].

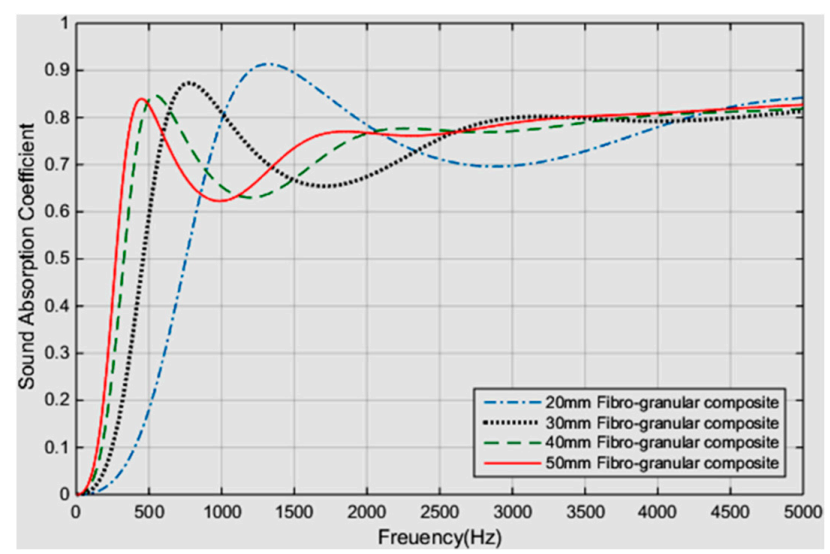

Figure 23. Effect of sample thickness on SAC [35].

They also validated the experimental measurement with the Johnson-ChampouxAllard (JCA) model, as shown in Figure 24. The Johnson-Champoux-Allard (JCA) model involves non-acoustical physical parameters, e.g., flow resistivity, tortuosity, porosity, viscous characteristic length, and thermal characteristic length. This model is widely used to describe the propagation of sound in porous media.

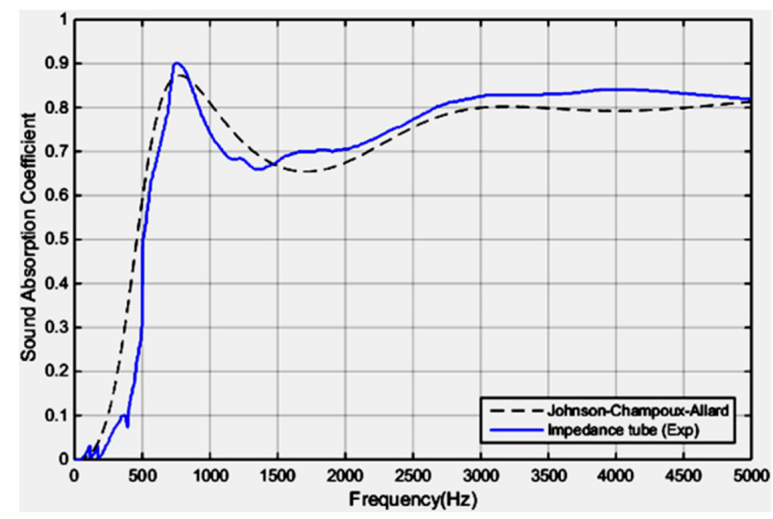

Figure 24. The sound absorption coefficient of fibro-granular composite to validate the analytical outcome through impedance tube measurement [35]. 
Taban et al. studied the sound absorption of palm-fruit-fiber-based composites. The effects of fiber density and sample thickness are shown in Figure 25 [60]. A higher thickness and relatively lower density resulted in better sound absorption.
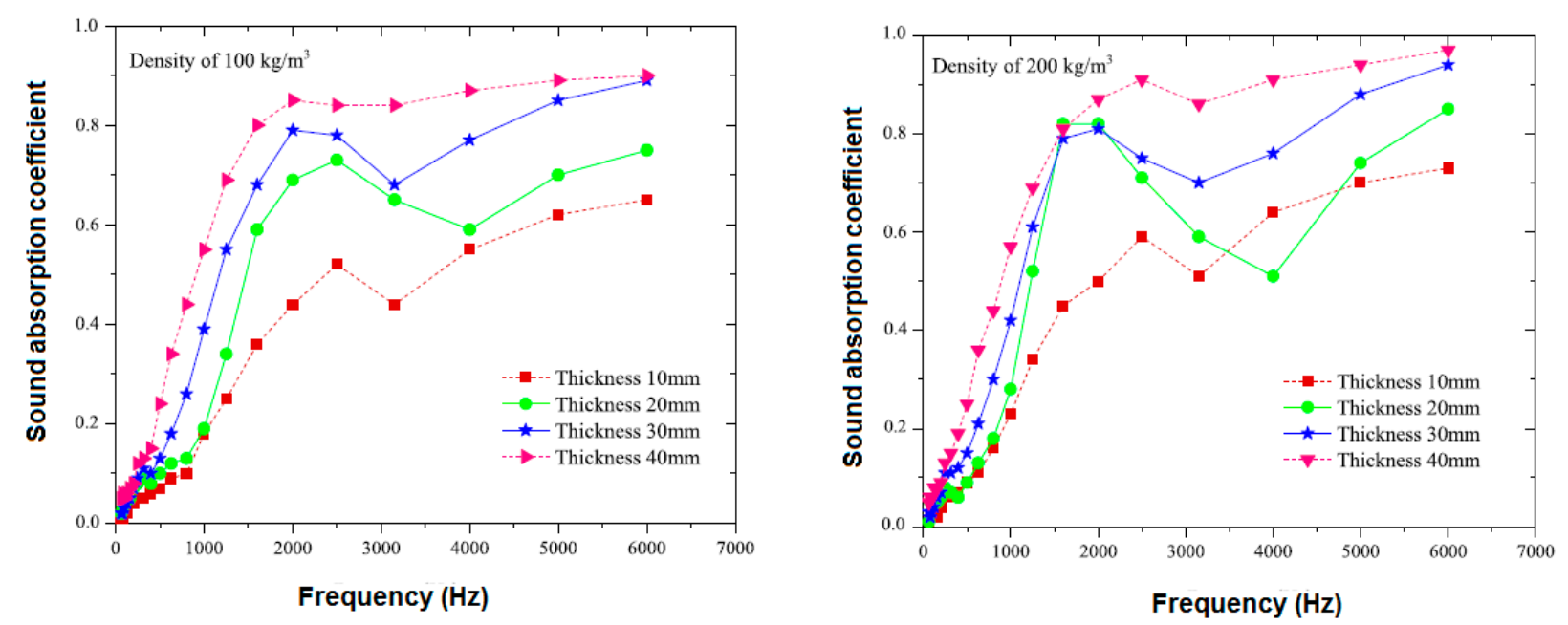

Figure 25. Effect of thickness and density onSAC of date-palm-fiber-based composites [60].

Shiney et al. investigated the acoustic properties of composite coir mats. Coir mats with different weaving patterns like Boucle weaving, Panama weaving, and Herringbone weaving were used along with the epoxy matrix. Acoustic properties were measured through an impedance tube in the frequency range of $250-2000 \mathrm{~Hz}$ by following the ISO10534-2 standard. It was concluded that for all structures, an increase in thickness of the sample results in an increase of sound absorption coefficient of the composite [61].

\subsubsection{Effect of Gluing and Multiple Layering of Composites}

Su et al. studied the effect of gluing multiple layers in a composite on the sound absorption behavior [62]. The sound propagation in multilayered composite is schematically shown in Figure 26.

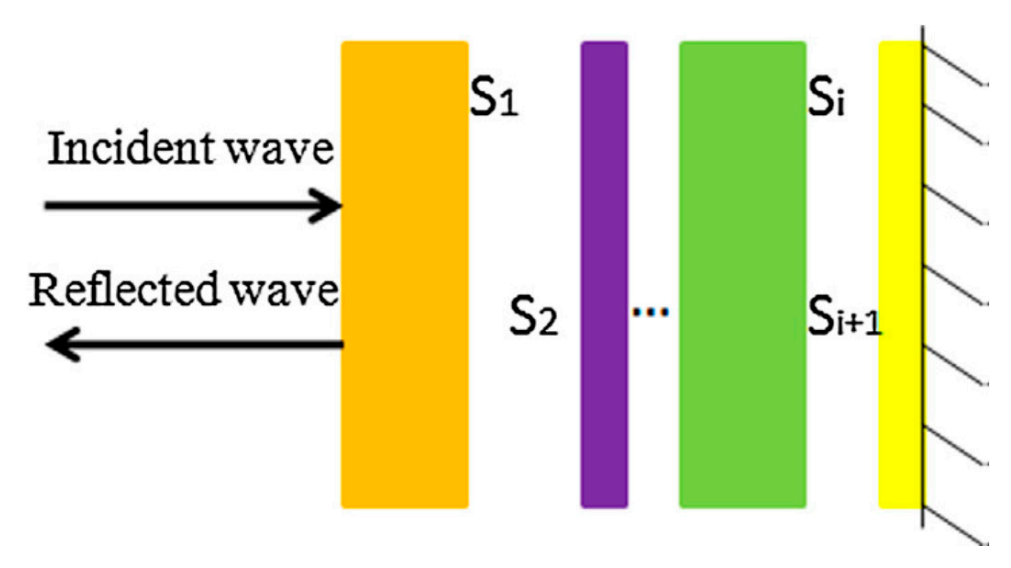

Figure 26. Sound propagation model of multilayer materials [62].

The effect of the damping factor of the gluing material on sound absorption coefficient of the multilayer composite is shown in Figure 27. 


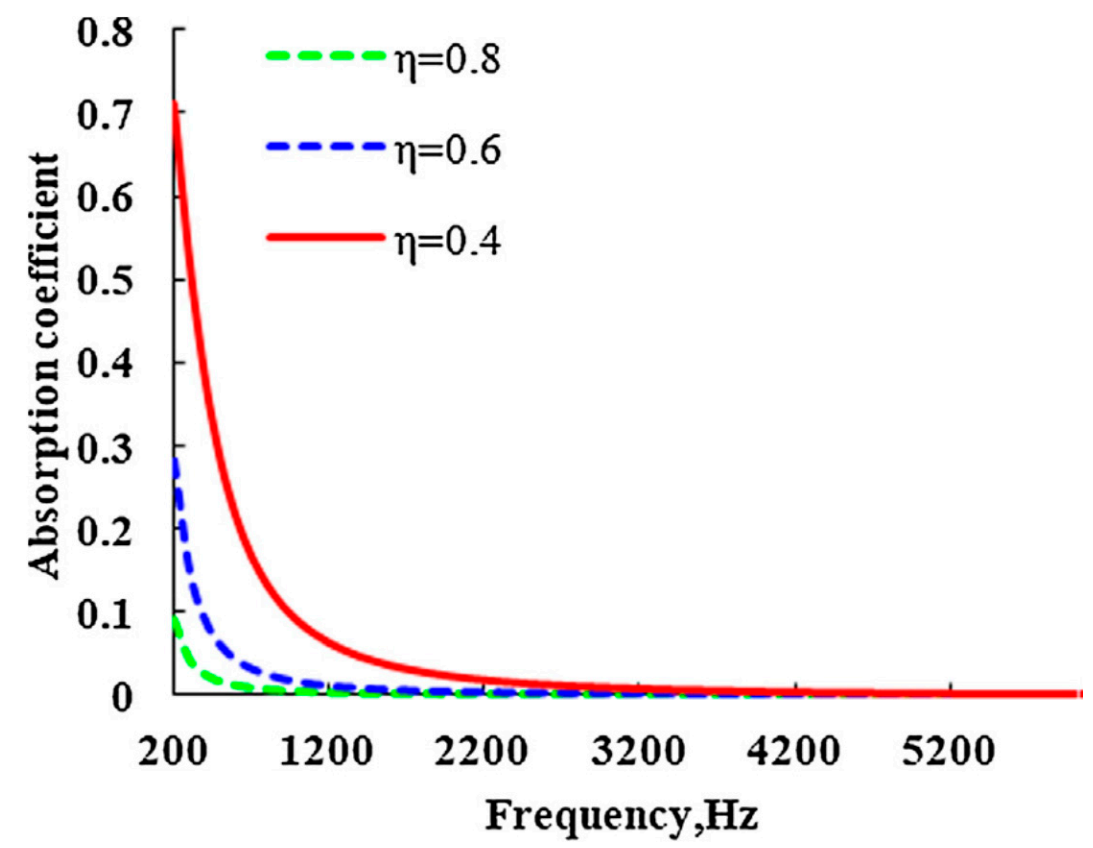

Figure 27. The effect of damping factor of gluing material on sound absorption coefficient [62].

The effect of damping factor of the gluing material on the sound transmission loss of the multilayer composite is shown in Figure 28.

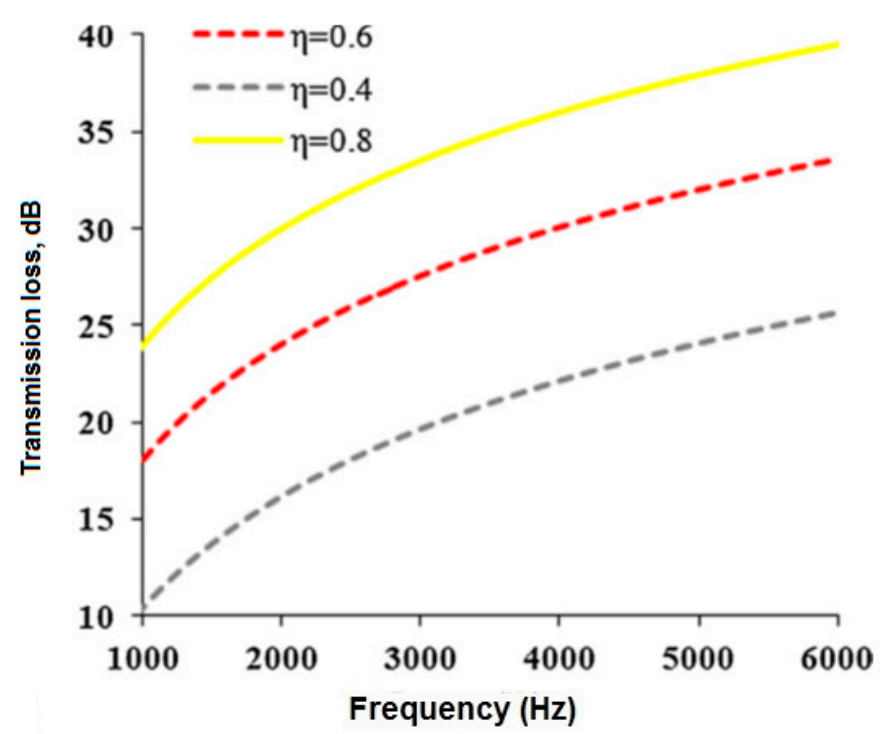

Figure 28. The effect of damping factor of gluing material on transmission loss [62].

\subsubsection{Effect of Perforation}

Yuvaraj et al. developed perforated acoustic panels from jute fiber based composites as shown in Figure 29 [63]. Substantial improvement in sound absorption performance was observed in the case of perforated panels as compared to non-perforated material of the same composition [64-68]. 


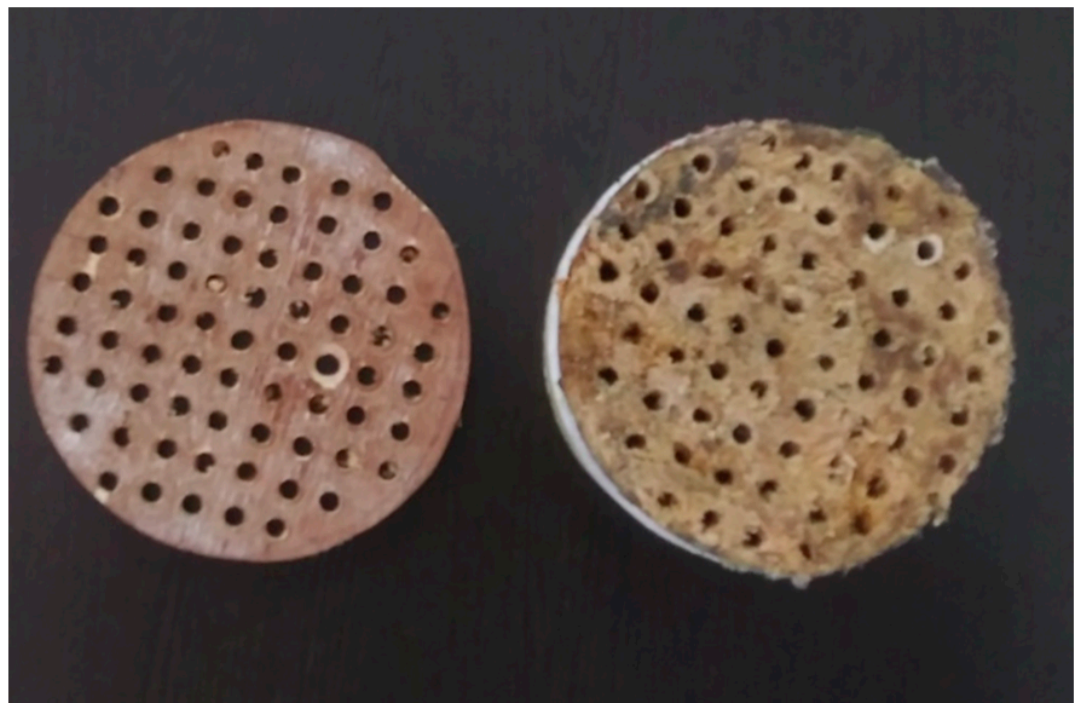

Figure 29. Perforated jute fiber composite panel [63].

Figure 30 shows the influence of $\%$ depth penetration on the sound absorption coefficient of the jute fiber based composites with a thickness of $1 \mathrm{~cm}$.

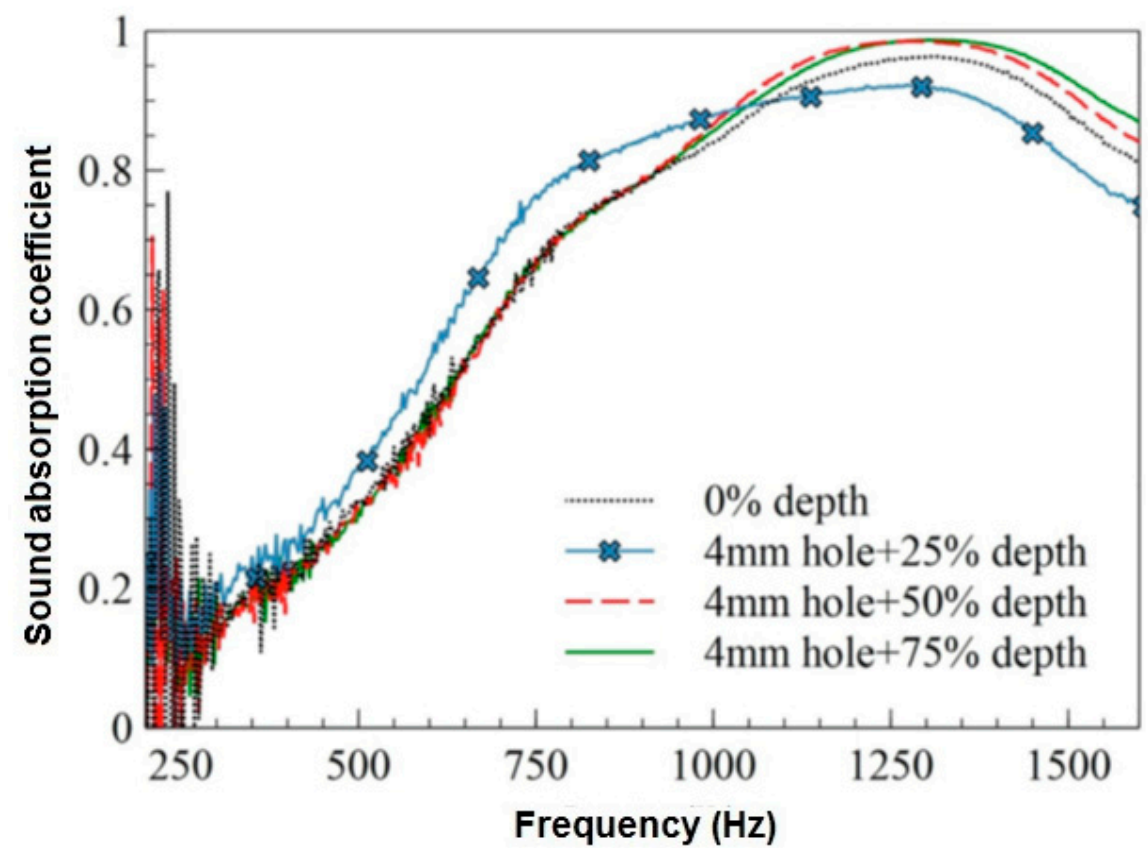

Figure 30. Effect of depth of perforation on the SAC of the jute-fiber-based composites [63].

Sound transmission loss for different perforation depths is shown in Figure 31. 


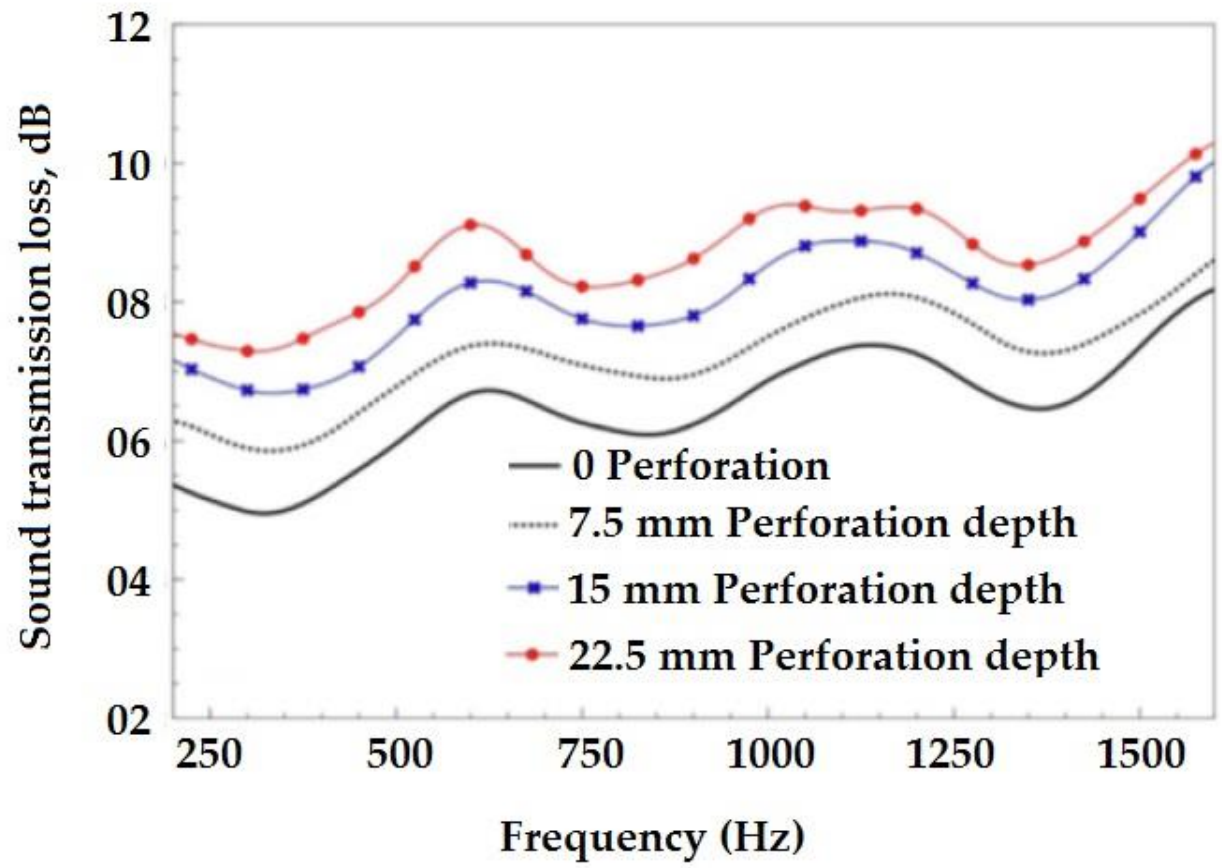

Figure 31. Effect of depth of perforation on sound transmission loss [63].

\subsubsection{Effect of Adding Plasticizer and Flame Retardants}

Researchers investigated the SAC of ramie-fiber-based polylactic acid composites. They used plain weave ramie fabric and short fibers for the manufacturing of composites with thickness $1 \mathrm{~cm}$. The results shown in Figure 32 reveal that by adding a plasticizer and/or flame-retardant finish, the sound absorption is improved [69].

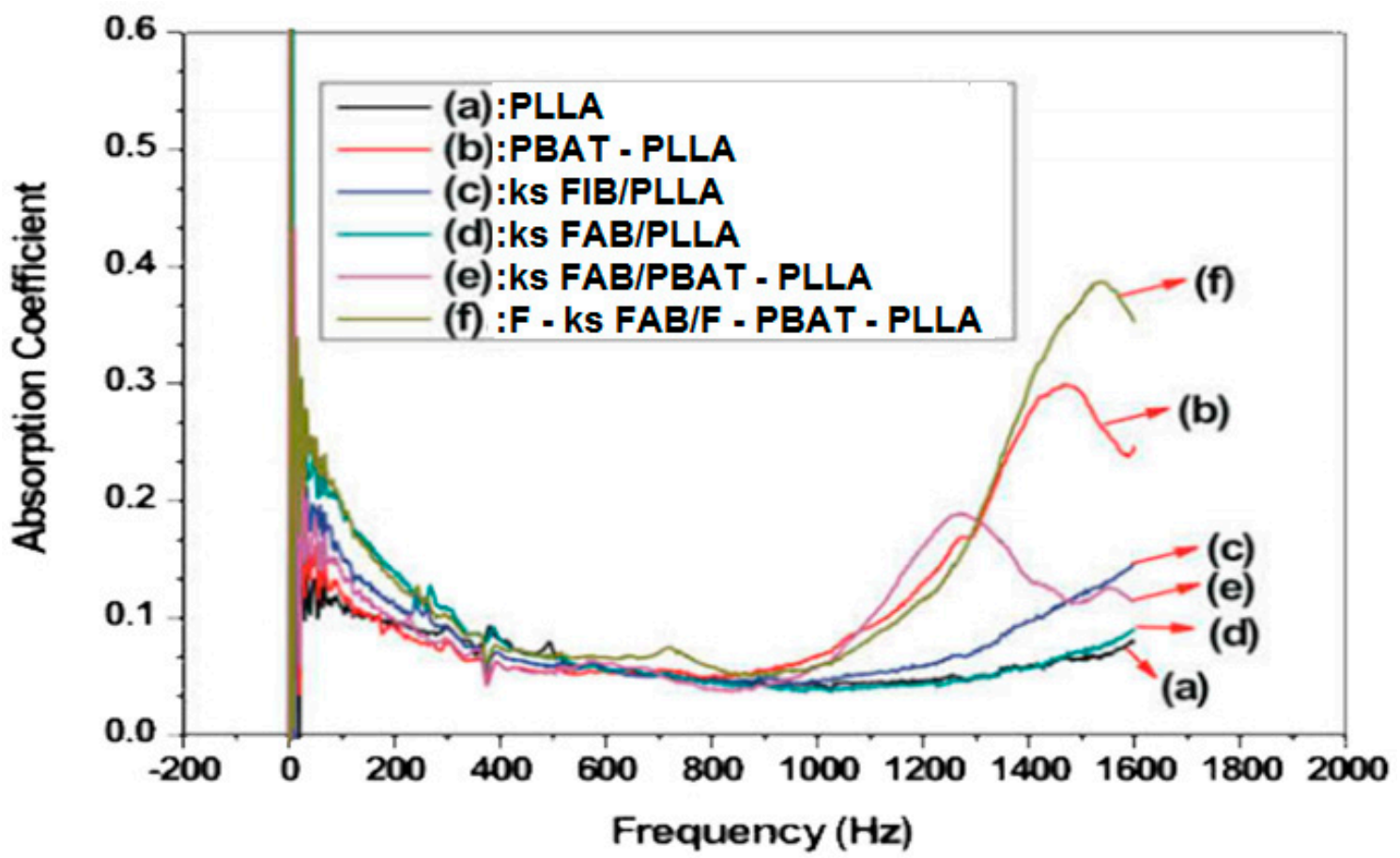

Figure 32. Effect of adding plasticizer on SAC of different composites [69]. PLLA: Poly L-Lactic acid, PBAT: poly(butylene adipate-co-terephthalate), ksFAB: ramie fabric treated by permanganate acetone solution and silane coupling agent, ksFIB: ramie fabric treated by permanganate acetone solution and silane coupling agent, F-ksFAB: ksFAB with flame retardant, F-PBAT-PLLA: PBAT-PLLA with flame retardant. 


\subsubsection{Effect of Frequency}

Elammaran Jayamani et al. further investigated the sound absorption of a betel-nutfiber-based polymer matrix composite. Unsaturated polyester (thermoset) and polypropylene (thermoplastic) were used as a matrix. It was found that by increasing frequency, the sound absorption coefficient of the betel-nut-fiber-based unsaturated polyester composite also increases. The sound absorption coefficient of sisal-fiber-based polylactic acid biocomposites was also reported. It was found that by increasing frequency, the sound absorption coefficient increases proportionally [69]. Yang et al. conducted a study on the acoustic properties of jute-, ramie-, and flax-fiber-based composites [25]. Samples were fabricated with $65 \%$ fiber volume fraction and overall thickness of $40 \mathrm{~mm}$. An impedance tube was used to measure the sound absorption coefficient with a frequency range of $63-10,000 \mathrm{~Hz}$. Researchers indicated that frequency has a significant effect on the sound absorption coefficient. An increase in sound absorption has been observed by increasing frequency. Initially from $0-1000 \mathrm{~Hz}$, rapid growth in sound absorption was recorded after the increase rate was reduced [70-75]. Several other researchers have reported on the influence of frequency on the acoustic properties of composite materials based on fibers [76-80]. The influence of frequency on the sound absorption coefficient of fiber-based lime-wool mortar is shown in Figure 33.

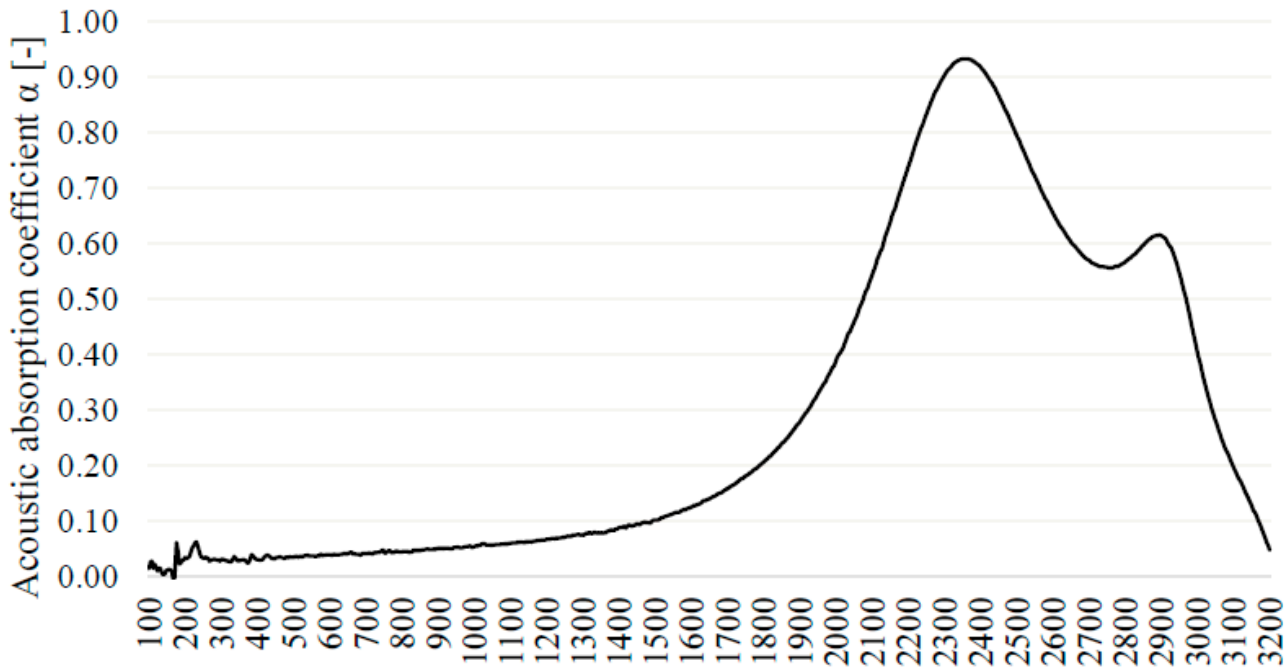

Frequency $[\mathrm{Hz}]$

Figure 33. The acoustic absorption coefficient of lime-wool mortar at different frequencies [76].

\subsubsection{Effect of Back Cavity Depth}

Sound absorption mainly occurs in a specific frequency range, which shifts to the lower region by increasing the depth of back cavity. Jiang et al. reported that absorption values are maximal in the range $450-900 \mathrm{~Hz}$, and there is a dependence between the thickness and the reduced frequency. There is a decrease in sound absorption as the cavity depth decreases. This type of behavior is a typical resonance effect [81]. The sound absorption coefficient for different depths of the back cavity is shown in Figure 34. 


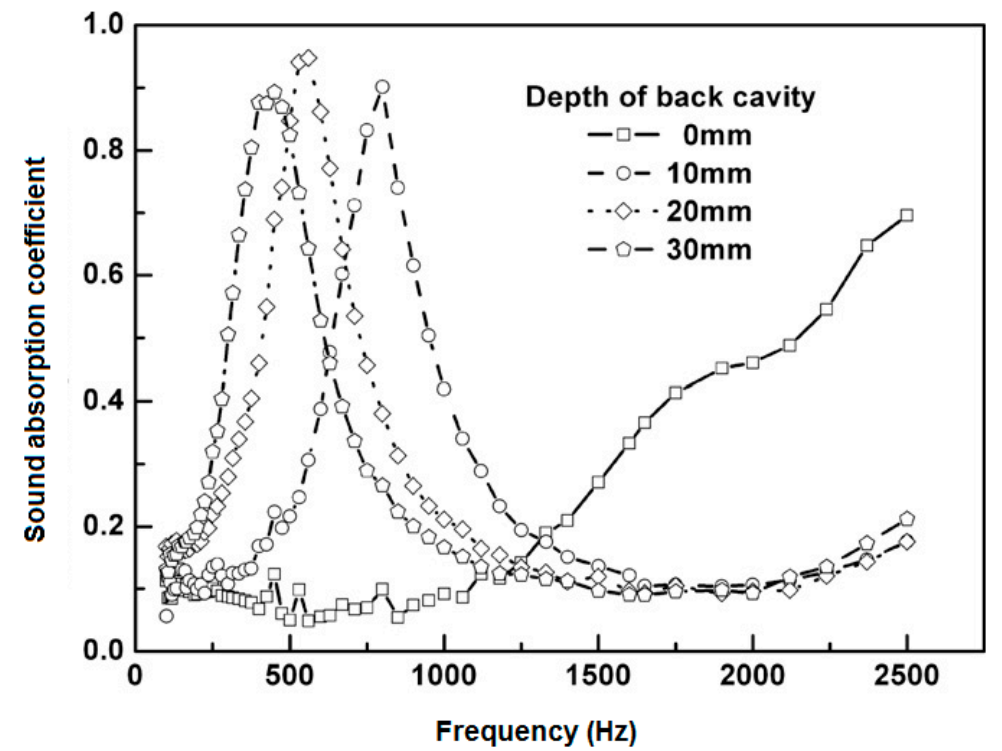

Figure 34. Effect of back cavity depth on the sound absorption performance of CPE/SHPF composites [81].

\subsubsection{Effect of Temperature}

Srivastava et al. investigated the effect of change in temperature on sound absorption. They found that the temperature change significantly affects the sound absorption coefficient [26]. Harris investigated the effect of temperature and humidity on sound absorption in the air. He used a frequency range of $2000-12,500 \mathrm{~Hz}$ and six temperatures ranging from $0.5^{\circ} \mathrm{C}$ to $25.1^{\circ} \mathrm{C}$ at normal atmospheric pressure. The effect of temperature on the noise attenuation coefficient with varying frequencies was measured. At $50 \%$ relative humidity, the results revealed that at low frequency, the temperature does not show any significant effect on the noise attenuation coefficient. However, at high frequency, the highest attenuation coefficient was recorded at the lowest temperature. Sound absorption continuously decreases with an increase in temperature [42].

Knudsen also investigated the effect of temperature and humidity on sound absorption in nitrogen, oxygen, and air. He used two reverberation chamber methods for measuring sound absorption. Results revealed that by increasing temperature, sound absorption decreases [46].

\subsubsection{Effect of Porosity and Tortuosity}

Researchers investigated the effect of porosity on the acoustic behavior of the material. If the porosity of the material is higher, then the sound waves come frequently in contact with the surface of the materials, which causes dissipation of acoustic energy. In addition to that, the size and number of pores are also very important for the sound absorption behavior of any material. When sound waves interact with the porous surface of the materials, the sound waves are damped [82]. By increasing volume porosity, SAC increases, as shown in Figure 35. 


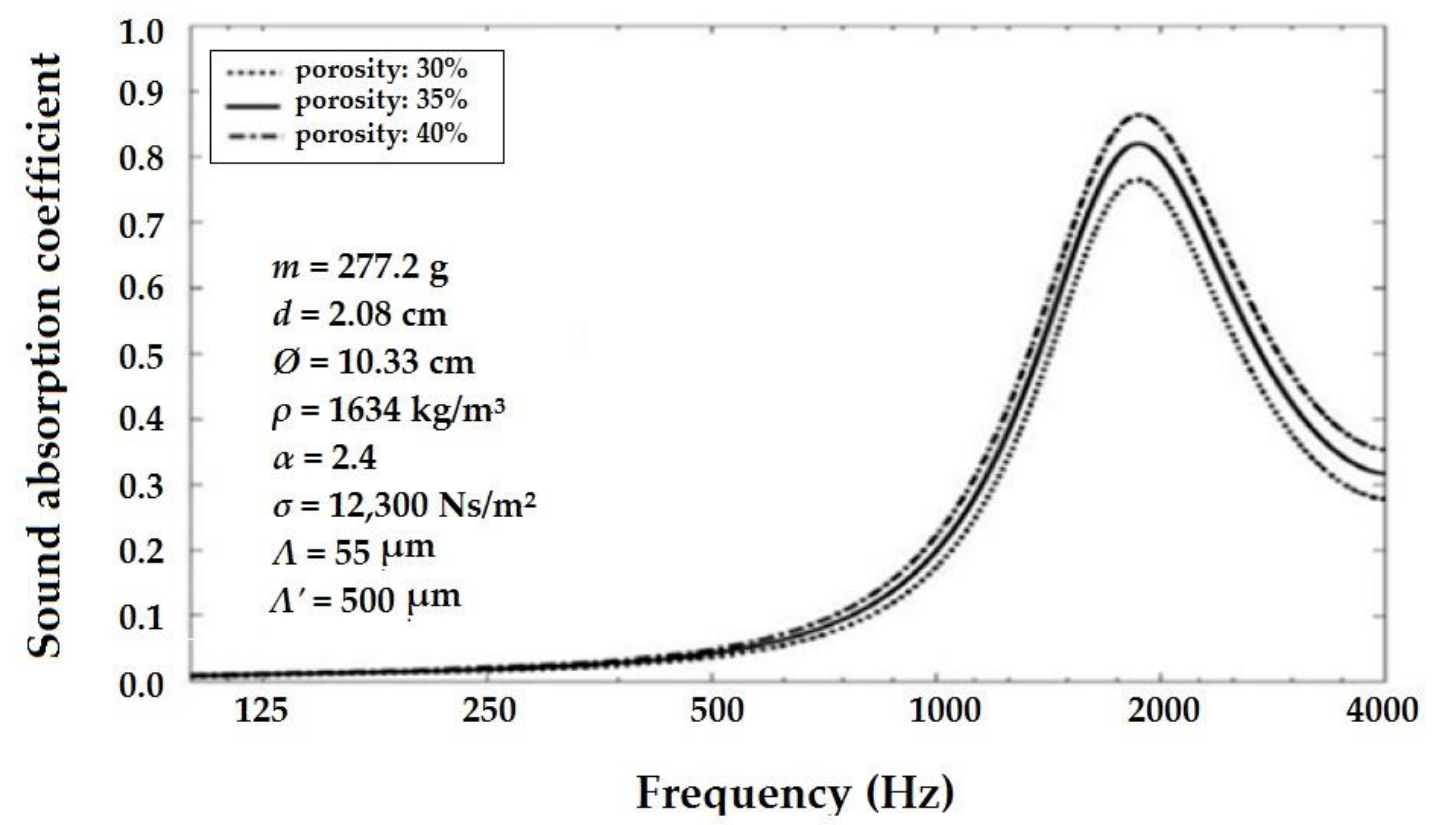

Figure 35. Effect of porosity on SAC [82].

Tortuosity is best described as the influence of internal structure on the acoustic properties of the materials. It is the elongation of the way through pores. Sakagami et al. investigated the acoustic properties of membrane-type sound absorbers. Results show that less tortuous materials can absorb more sound as compared to more tortuous materials. Highly tortuous materials are more likely prone to large fluctuations in the sound absorption coefficient. Researchers also stated that tortuosity does not have a significant effect on noise transmission coefficient [83]. Dupont et al. described that by increasing porosity, sound absorption will also be increased [49].

\subsubsection{Effect of Flow Resistivity}

Flow resistivity is the ability to resist airflow from entering the core of any material. It can also be defined as a measure of how much air can enter into a porous material. It is one of the key factors that affect acoustic properties. The acoustic properties of materials are affected by the flow resistance per unit thickness of the absorber material. In non-woven materials, the interlocking of the fibers gives enough friction to resist the motion of sound waves. When sound waves pass through the rough and tortuous path, they cause friction, which results in a decrease in wave amplitude, and sound wave energy is converted into heat [84]. According to Crocker, if the flow resistivity value of a material is higher, then airflow resistance will be higher as well. Sometimes materials with too-high airflow resistance result in more sound reflection than absorption [51]. The acoustic properties of materials mainly depend on intrinsic properties. The transmission loss of the sound when it passes through a porous material mainly depends on the sound wave frequency, thickness, and flow resistivity of the material. By increasing flow resistivity, transmission loss will also be increased. Airflow resistivity has an inverse relation to air permeability. Moreover, as the airflow resistivity of the material increases, then it is difficult for sound waves to enter the material. Hence, sound absorption shows a significant decrease $[85,86]$.

\subsubsection{Effect of Density}

Density is known to be one of the most important parameters that affect the acoustic properties of materials. It was found that by increasing the density of the fibrous material, the sound absorption coefficient also increases, especially at higher and medium frequencies. Koizumi et al. investigated the effect of density on the acoustic properties of materials. They concluded that density has a direct relation to SAC at high and medium frequen- 
cies [32]. Ballagh et al. studied the effect of bulk density of wool fiber on sound absorption of the material. It was found that materials having relatively lower densities have higher sound absorption at low frequencies as compared to higher density materials, which absorb high and middle-frequency sound waves. It is further described that wool fibers perform very well at higher density with a frequency equal to or more than $500 \mathrm{~Hz}$, because at higher frequencies, surface friction increases, which causes the dissipation of more sound energy. By increasing the density of materials, fiber per unit area will also be increased, which increases the sound absorption coefficient, as shown in Figures 8 and 9 [53].

\subsubsection{Effect of Compression}

According to Castagnede et al. and Wang et al., the compression of fibrous or porous material causes an increase in the sound absorption coefficient, as shown in Figure 36. It is because by compression, the constituting fibers come closer to each other, thus increasing density and decreasing the thickness. Further, an increase in compression causes an increase in tortuosity as well as flow resistivity, which decreases the shape factor $[87,88]$.

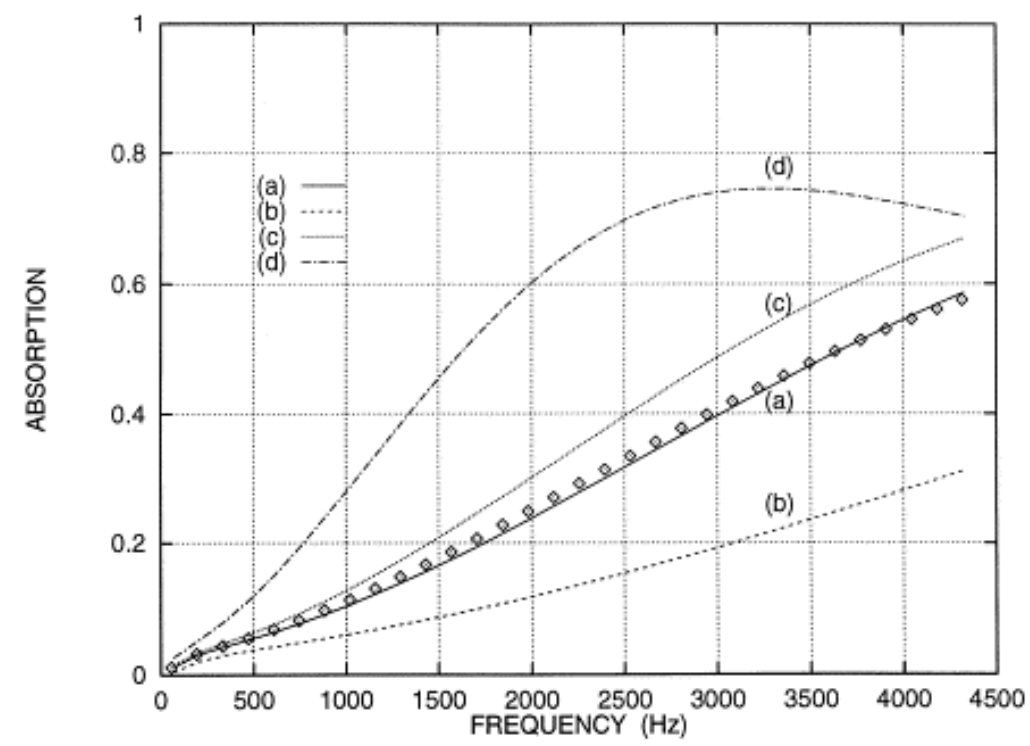

Figure 36. Effect of compression rate on SAC [87].

Nor et al. studied the effect of compression on the acoustic properties of coconut coir fibers. Experiments of coir fiber with different compression levels were conducted by an impedance tube with $28 \mathrm{~mm}$ diameter, and standard ISO-10534-2 were used to validate the analytical model. Samples were tested at different compression levels leading to different thicknesses, e.g., 50, 35, and $20 \mathrm{~mm}$. It is obvious that compression significantly affects the physical parameters like flow resistivity, porosity, and tortuosity of the samples. Results revealed that compression reduces the porosity of the sample, and it shifts the absorption towards a higher frequency. Moreover, a higher compression rate causes an increase in sound absorption [89].

Keshavarz et al. described that the compression of materials may cause an increase or decrease in the sound absorption coefficient, which mainly depends on the method of compression. The results indicated that increases in compression lead to decreases in the sound absorption coefficient in the low and medium frequency region for samples with thickness of $2 \mathrm{~cm}$. For high frequencies, compression improves the absorption coefficient, as shown in Figure 37 [90]. 
a

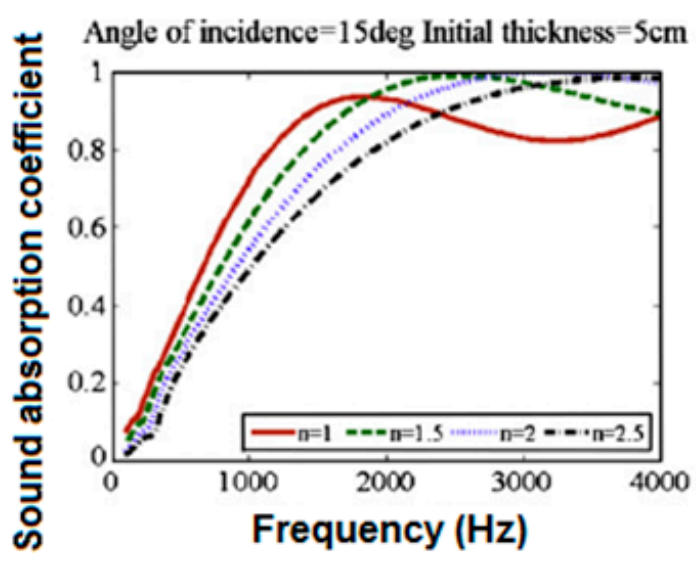

b

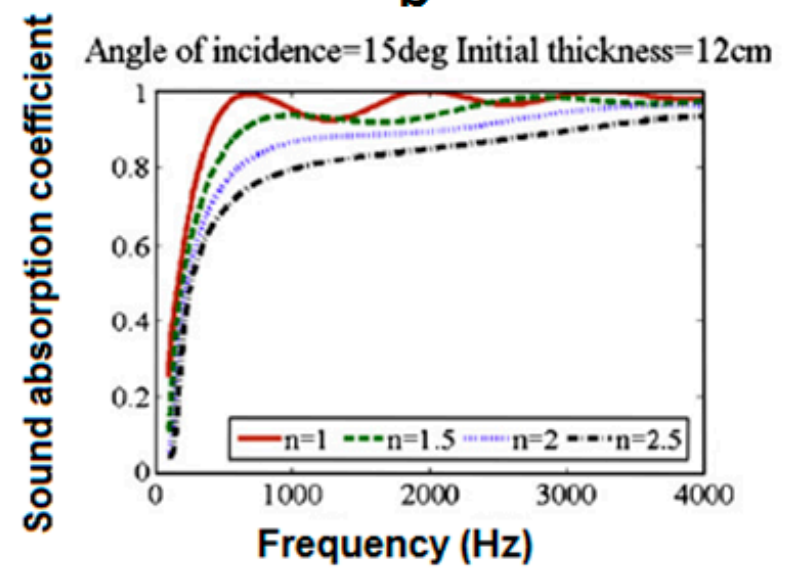

C

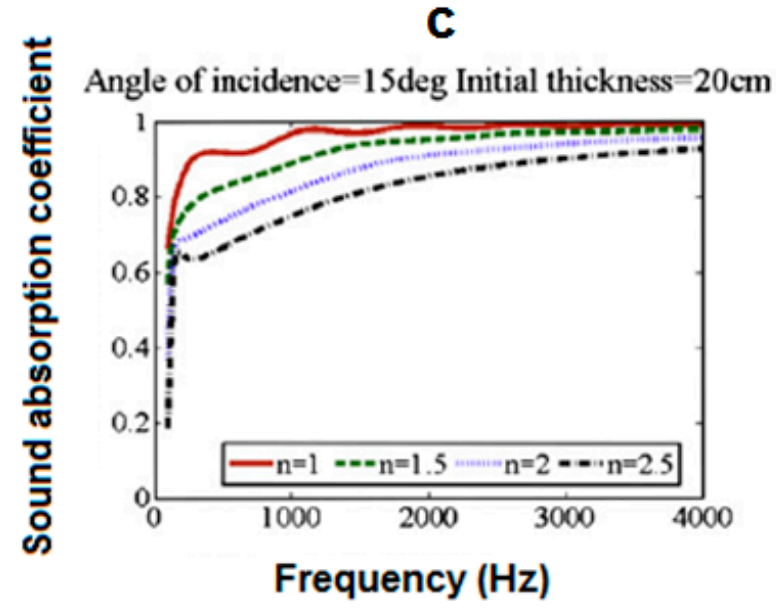

Figure 37. Influence of initial thickness and angle of sound incidence on SAC [90].

\subsubsection{Effect of Location of Sound Absorbers}

Everest investigated the effect of placement of the active absorbent material on sound absorption. The sound absorber was placed at different positions such as ends, sides, and the vertical, traverse, and longitudinal modes on the ceiling. The results revealed that placement of sound absorbers along the edges and near corners of a rectangular room shows effective absorption of the sound [91,92].

Lu et al. studied the effect of placement on the acoustic properties of the materials. They concluded that if an air gap is added behind the sample, it will change the absorption behavior. Hence, the sound absorption of the materials is significantly increased by the addition of an air gap between the sample and back surface [93].

S. Fatima et al. conducted studies on the effect of rigid backing and airgap backing of treated and untreated jute fiber composites. Commercial grade jute fibers named TD5 were used in their study. An impedance tube was used with a frequency range of 0-4000 Hz. Air gaps of 25.4 and $50.8 \mathrm{~mm}$ were used between sample and rigid backing during testing. Results revealed that a $50.8 \mathrm{~mm}$ air gap results in the highest sound absorption coefficient, while rigid backing without an air gap leads to the lowest sound absorption coefficient. Hence, by increasing the air gap between the sample and rigid backing, the sound absorption coefficient can also be increased [55].

A detailed account of several fiber-based composite sound-absorbing materials as reported by various researchers is given in Table 2 . 
Table 2. Summary of acoustical properties of fiber-based composites.

\begin{tabular}{|c|c|c|c|c|c|c|}
\hline No. & Reinforcement & Matrix & $\begin{array}{c}\text { Sample } \\
\text { Parameters }\end{array}$ & $\begin{array}{l}\text { Fabrication } \\
\text { Method }\end{array}$ & Results/SAC & Ref\# \\
\hline 1 & Banana Fiber & Epoxy & $\begin{array}{c}\text { Fiber loading } 20 \% \\
\text { wt.\%, Thickness } \\
20 \mathrm{~mm}\end{array}$ & $\begin{array}{l}\text { Hot Compression } \\
\left(1000 \text { psi } 24^{\circ} \mathrm{C}\right)\end{array}$ & $0.11(6000 \mathrm{~Hz})$ & [48] \\
\hline 2 & Ramie Fiber & $\begin{array}{l}\text { Poly L Lactic } \\
\text { Acid (PLLA) }\end{array}$ & $\begin{array}{l}\text { Thickness } 3 \mathrm{~mm} \text {, } \\
\text { Fiber Loading } \\
\text { 30\% wt. } \%\end{array}$ & $\begin{array}{c}\text { Hot Pressing } \\
\text { (Pressure } 20 \mathrm{MPa} \text {, } \\
\text { Temperature } \\
170^{\circ} \mathrm{C} \text {, Time } 4 \text { min }\end{array}$ & $0.12(1600 \mathrm{~Hz})$ & [49] \\
\hline \multirow{4}{*}{3} & Oil Seed Waste & \multirow{4}{*}{$\begin{array}{l}\text { Formaldehyde } \\
\text { Resin }\end{array}$} & \multirow{4}{*}{-} & \multirow{4}{*}{ - } & $0.8(3200 \mathrm{~Hz})$ & \multirow{4}{*}[50]{} \\
\hline & Fiber Glass waste & & & & $0.9(3200 \mathrm{~Hz})$ & \\
\hline & Wood Waste & & & & $0.9(3200 \mathrm{~Hz})$ & \\
\hline & Steel Slag & & & & $0.65(3200 \mathrm{~Hz})$ & \\
\hline 4 & Rice Straw & $\begin{array}{c}\text { Urea } \\
\text { Formaldehyde }\end{array}$ & $\begin{array}{l}\text { Thickness } 10 \mathrm{~mm} \text {, } \\
\text { fiber loading of } \\
\text { 0-30 wt. } \%\end{array}$ & $\begin{array}{l}\text { Hot compression } \\
\left(500 \text { psi } 140^{\circ} \mathrm{C}\right)\end{array}$ & $\begin{array}{c}0.05-0.5 \\
(8000 \mathrm{~Hz})\end{array}$ & [51] \\
\hline \multirow{3}{*}{5} & Ramie Fiber & \multirow{3}{*}{ Epoxy } & \multirow{3}{*}{ Thickness $3 \mathrm{~mm}$} & \multirow{3}{*}{$\begin{array}{l}\text { Hot Press } \\
\text { Compression } \\
\text { Machine }\end{array}$} & $0.6(2000 \mathrm{~Hz})$ & \multirow{3}{*}[52]{} \\
\hline & Flax & & & & $0.65(2000 \mathrm{~Hz})$ & \\
\hline & Jute & & & & $0.65(2000 \mathrm{~Hz})$ & \\
\hline \multirow{2}{*}{6} & Sugarcane Bagasse & \multirow{3}{*}{ Polyester Resin } & \multirow{3}{*}{ Fiber Loading 30\% } & \multirow{3}{*}{ - } & $0.63(4000 \mathrm{~Hz})$ & \multirow{3}{*}{ [53] } \\
\hline & Banana Fiber & & & & $0.68(4000 \mathrm{~Hz})$ & \\
\hline 7 & Hybrid Composite & & & & $0.73(4000 \mathrm{~Hz})$ & \\
\hline \multirow{2}{*}{8} & \multirow{2}{*}{ Hemp } & \multirow{2}{*}{ Recycled latex } & Thickness 300 mm & \multirow{2}{*}{-} & $0.50(2000 \mathrm{~Hz})$ & \multirow{2}{*}{ [54] } \\
\hline & & & Thickness $40 \mathrm{~mm}$ & & $0.50(3000 \mathrm{~Hz})$ & \\
\hline \multirow[t]{2}{*}{9} & Rice straw & Polypropylene & \multirow{2}{*}{$\begin{array}{l}\text { Fiber Loading } \\
\text { 10\% wt. } \%\end{array}$} & \multirow{2}{*}{$\begin{array}{c}\text { Hot Pressing } \\
\text { Machine, Pressure } \\
1000 \text { psi, } \\
\text { Temperature } \\
190^{\circ} \mathrm{C} \text {, Time } \\
30 \mathrm{~min} \\
\end{array}$} & $0.08(2000 \mathrm{~Hz})$ & \multirow[t]{2}{*}[55]{} \\
\hline & Kenaf & $\begin{array}{l}\text { Urea- } \\
\text { formaldehyde }\end{array}$ & & & $0.065(2000 \mathrm{~Hz})$ & \\
\hline 10 & Sisal Fibers & $\begin{array}{l}\text { Poly Lactic } \\
\text { Acid }\end{array}$ & $\begin{array}{l}\text { Fiber Loading 30\%, } \\
\text { Thickness } 8 \mathrm{~mm}\end{array}$ & Hot Press Machine & $0.085(2000 \mathrm{~Hz})$ & [56] \\
\hline \multirow{6}{*}{11} & Coconut/Coir & & \multirow{6}{*}{$\begin{array}{l}\text { Fiber Loading 20\%, } \\
\text { Thickness } 10 \mathrm{~mm}\end{array}$} & \multirow{6}{*}{$\begin{array}{c}\text { Compression } \\
\text { Molding } \\
\text { Machine, Pressure } \\
7 \mathrm{MPa} \text {, Time } 24 \mathrm{~h}, \\
\text { Temperature } 24^{\circ} \mathrm{C} \text {. }\end{array}$} & $0.086(6000 \mathrm{~Hz})$ & \multirow{6}{*}[57]{} \\
\hline & Kenaf & Epoxy & & & $0.085(6000 \mathrm{~Hz})$ & \\
\hline & Sugarcane & & & & $0.083(6000 \mathrm{~Hz})$ & \\
\hline & Ramie & $\begin{array}{l}\text { Poly-(I-Lactic } \\
\text { acid) }\end{array}$ & & & $0.089(1600 \mathrm{~Hz})$ & \\
\hline & Wheat straw & Polypropylene & & & $0.03(1800 \mathrm{~Hz})$ & \\
\hline & Jute & Zein & & & $0.06(5000 \mathrm{~Hz})$ & \\
\hline \multirow{2}{*}{12} & \multirow{2}{*}{$\begin{array}{l}\text { Seven-hole hollow } \\
\text { polyester fibers } \\
\text { (SHPF) }\end{array}$} & \multirow{2}{*}{$\begin{array}{l}\text { Chlorinated } \\
\text { polyethylene } \\
\text { (CPE) }\end{array}$} & $\begin{array}{l}\text { Thickness } 1 \text { mm, } \\
\text { Fiber Loading 20\%) }\end{array}$ & - & $0.42(2500 \mathrm{~Hz})$ & \multirow[t]{2}{*}{ [58] } \\
\hline & & & $\begin{array}{l}3 \mathrm{~mm}(\text { Fiber } \\
\text { Loading 20\%) }\end{array}$ & & $0.695(2500 \mathrm{~Hz})$ & \\
\hline
\end{tabular}


Table 2. Cont.

\begin{tabular}{|c|c|c|c|c|c|c|}
\hline No. & Reinforcement & Matrix & $\begin{array}{c}\text { Sample } \\
\text { Parameters }\end{array}$ & $\begin{array}{l}\text { Fabrication } \\
\text { Method }\end{array}$ & Results/SAC & Ref\# \\
\hline 13 & Wheat straw & Polypropylene & $\begin{array}{c}\text { Thickness of } 3.2 \\
\text { mm, } \\
\text { fiber loading of } \\
40-80 \mathrm{wt} . \%\end{array}$ & Hot compression & $\begin{array}{l}0.03-0.23 \\
(3000 \mathrm{~Hz})\end{array}$ & [59] \\
\hline \multirow{5}{*}{14} & Flax & \multirow{5}{*}{$\begin{array}{l}\text { Bisphenol-A } \\
\text { base Epoxy }\end{array}$} & \multirow{5}{*}{ Fiber Loading 60\%, } & \multirow{5}{*}{$\begin{array}{c}\text { Hot-pressing } \\
\text { method, Pressure } \\
2.5 \mathrm{MPa}, \\
\text { Temperature } 120^{\circ} \mathrm{C}\end{array}$} & $0.369(10 \mathrm{kHz})$ & \multirow{5}{*}[60]{} \\
\hline & Carbon & & & & $0.293(10 \mathrm{kHz})$ & \\
\hline & Glass & & & & $0.324(10 \mathrm{kHz})$ & \\
\hline & Ramie & & & & $0.32(10 \mathrm{kHz})$ & \\
\hline & Jute & & & & $0.419(10 \mathrm{kHz})$ & \\
\hline \multirow[t]{2}{*}{15} & Flax & \multirow[t]{2}{*}{ Epoxy resin } & \multirow[t]{2}{*}{$\begin{array}{l}\text { Fiber loading 50\%, } \\
\text { Thickness } 4 \mathrm{~mm}\end{array}$} & \multirow[t]{2}{*}{$\begin{array}{l}\text { Hot press machine } \\
\text { under pressure of } \\
1 \mathrm{MPa} \text { and } \\
\text { temperature of } \\
120^{\circ} \mathrm{C} \text { for } 2 \mathrm{~h} \text { for } \\
\text { complete curing }\end{array}$} & $0.96(3200 \mathrm{~Hz})$ & \multirow[t]{2}{*}[61,62]{} \\
\hline & Balsa Wood & & & & $0.58(3200 \mathrm{~Hz})$ & \\
\hline \multirow{5}{*}{16} & Lufa & Epoxy & \multirow{5}{*}{$\begin{array}{l}\text { Fiber Loading 25\%, } \\
\text { Thickness } 5 \mathrm{~mm}\end{array}$} & \multirow{5}{*}{$\begin{array}{l}\text { Hot and cold } \\
\text { compression } \\
\text { hydraulic press } \\
\text { machine }\end{array}$} & $0.095(500-6000 \mathrm{~Hz})$ & \multirow{5}{*}{ [63] } \\
\hline & Betel Nut & $\begin{array}{l}\text { Unsaturated } \\
\text { Polyester } \\
(\mathrm{MEKP})\end{array}$ & & & $0.085(500-6000 \mathrm{~Hz})$ & \\
\hline & Sisal & Poly-lactic Acid & & & $0.10(500-6000 \mathrm{~Hz})$ & \\
\hline & Rice Straw & Polypropylene & & & $0.12(500-6000 \mathrm{~Hz})$ & \\
\hline & Oil palm & Zein & & & $0.095(500-6000 \mathrm{~Hz})$ & \\
\hline 17 & Banana Fiber & Epoxy Resins & Fiber Loading 20\% & $\begin{array}{c}\text { Hydraulic hot/cold } \\
\text { press machine, } \\
\text { Pressure } 10 \mathrm{MPa}\end{array}$ & $0.1(500-6000 \mathrm{~Hz})$ & [64] \\
\hline 18 & Flax & Epoxy & Thickness of $3 \mathrm{~mm}$ & $\begin{array}{l}\text { Compression } \\
\text { (laminated) }\end{array}$ & $0.11(2000 \mathrm{~Hz})$ & {$[65]$} \\
\hline
\end{tabular}

\section{Conclusions}

In this review, the details of various factors affecting the acoustic behavior of naturalfiber-based materials and their composites were summarized. Natural fibers have relatively good sound absorption capability due to their porous structure. Fiber-based composites are widely used in buildings and constructions due to their good mechanical and acoustic insulation properties. Researchers found certain factors that affect the SAC of FRCs, i.e., fiber diameter, fiber type, fiber content, frequency, alkali treatment, sample thickness, fiber length, fiber orientation, and addition of plasticizer and/or fire-retardant finish [88-93]. Results reported by various researchers reveal that by increasing the content, frequency, sample thickness, and fiber inclination of fibers, the SAC of their composites will also be increased. Decreasing fiber diameter causes an increase in the SAC of composites. Alkali treatment of fibers causes enhancement of sound absorption. Further, random orientations of fibers in composites can absorb sound more efficiently than aligned fibers. The addition of a plasticizer and fire retardant finish to composites causes a further increase in the SAC.

Author Contributions: All authors contributed to this review. Conceptualization, T.H., H.J. R.M., M.P. and M.M.; methodology, T.H., M.Q.K. and M.T.; software, H.J. R.M., M.P. and M.M.; formal analysis, T.H., H.J. R.M., M.Q.K., M.P., M.T. and M.M.; resources, H.J. R.M., M.P., M.T. and M.M.; writing—original draft preparation, T.H., H.J. R.M., M.Q.K., M.P., M.T. and M.M.; writing-review and editing, T.H., H.J. R.M., M.Q.K., M.P., M.T. and M.M.; supervision, H.J. R.M., M.P. and M.M.; 
project administration, H.J. R.M., M.P., M.T. and M.M.; funding acquisition, R.M., M.P., M.T. and M.M. All authors have read and agreed to the published version of the manuscript.

Funding: The work was supported by the internal grant agency of the Faculty of Engineering, Czech University of Life Sciences Prague (no. 2021:31140/1312/3108), project: Optimization of performance and comfort properties of fire-resistant knitwear (No. NRPU/HEC/8980), project: "Development of comfortable compression socks for treatment of varicose veins or chronic venous disease in legs" under HEC project Establishment of Technology Development Fund (TDF) (No.TDF03-149), and by the Ministry of Education, Youth and Sports of the Czech Republic, the European Union (European Structural and Investment Funds-Operational Program Research, Development and Education) in the frames of the project "Modular platform for autonomous chassis of specialized electric vehicles for freight and equipment transportation", Reg. No. CZ.02.1.01/0.0/0.0/16_025/0007293.

Institutional Review Board Statement: Not applicable.

Informed Consent Statement: Not applicable.

Data Availability Statement: No data is associated with this work.

Conflicts of Interest: The authors declare no conflict of interest.

\section{References}

1. Erden, S.; Kingsley, H. Fiber reinforced composites. In Fiber Technology for Fiber-Reinforced Composites; Woodhead Publishing: Cambridge, UK, 2017; pp. 51-79.

2. Vallittu, P.; Akikazu, S. Structural Properties of Dental FRC Structures. A Clinical Guide to Fiber Reinforced Composites (FRCs) in Dentistry; Woodhead Publishing: Cambridge, UK, 2017; pp. 35-56.

3. Pickering, K.L.; Efendy, M.G.A.; Le, T.M. A review of recent developments in natural fiber composites and their mechanical performance. Compos. Part A Appl. Sci. Manuf. 2016, 83, 98-112. [CrossRef]

4. Cao, Y.; Wu, Y. Evaluation of statistical strength of bamboo fiber and mechanical properties of fiber reinforced green composites. J. Central South Univ. Technol. 2008, 15, 564-567. [CrossRef]

5. N. C. United States Department of Health and Human Services. Report on Carcinogens, 12th ed.; National Toxicology Program: Raleigh, NC, USA, 2012.

6. Kogel, J.E.; Trivedi, N.C.; Barker, J.M.; Krukowski, S.T. Industrial Minerals E Rocks: Commodities, Markets, and Uses, 7th ed.; SME: Englewood, CO, USA, 2006; Available online: www.smenet.org (accessed on 29 May 2021).

7. Hubaux, R.; Becker-Santos, D.D.; Enfield, K.S.S.; Lam, S.; Lam, W.L.; Martinez, V.D. Arsenic, asbestos and radon: Emerging players in lung tumorigenesis. Environ. Health 2012, 11, 89. [CrossRef] [PubMed]

8. Rouette, H.K.; Schwager, B. Encyclopedia of Textile Finishing, 1st ed.; Springer: Berlin, Germany, 2001; Volume 23.

9. Su, W.C.; Cheng, Y.S. Deposition of man-made fibers in human respiratory airway casts. J. Aeros. Sci. 2009, 40, 270-284. [CrossRef]

10. Fragomeni, S.; Venkatesan, S. Incorporating Sustainable Practice in Mechanics and Structures of Materials; CRC Press: Boca Raton, FL, USA, 2010

11. Mamtaz, H.; Fouladi, M.; Al-Atabi, H.M.; Namasivayam, S.N. Acoustic absorption of natural fiber composites. J. Eng. 2016, 2016, 5836107. [CrossRef]

12. Kadam, V.V.; Nayak, R. Basics of Acoustic Science; Springer Science \& Business Media: Singapore, 2016.

13. ASTM. ASTM C423-17. Standard Test Method for Sound Absorption and Sound Absorption Coefficients by the Reverberation Room Method; 1850 M Street, NW, Suite 1030; ASTM: Washington, DC, USA, 2017.

14. Kang, Z.; Song, R.; Zhang, H.; Liu, Q. Study on sound insulation performance of double-layer perforated panelunder normal incidence waves. Appl. Acoust. 2021, 174, 107785. [CrossRef]

15. Yiyao, L.; Wana, B.; Chuanren, D.; Sakanishi, A. The non-linear model of sound wave diffusion in Chrysanthemum callus. Colloid Surf. B Biointerfaces 2002, 24, 333-337. [CrossRef]

16. Nowoswiat, A.; Bochen, J.; Dulak, L.; Zuchowski, R. Investigation studies involving sound absorbing parameters of roadsidescreen panels subjected to aging in simulated conditions. Appl. Acoust. 2016, 111, 8-15. [CrossRef]

17. Zhang, Y.; Li, H.; Abdelhady, A.; Yang, J. Effect of different factors on sound absorption property of porous concrete. Transp. Res. Part D Trans. Environ. 2020, 87, 102532. [CrossRef]

18. Rey, R.D.; Alba, J.; Arenas, J.P.; Sanchis, V.J. An empirical modelling of porous sound absorbing materials made of recycled foam. Appl. Acoust. 2012, 73, 604-609. [CrossRef]

19. Cox, T.J.; Antonio, P.D. Acoustic Absorbers and Diffusers: Theory, Design and Application, 3rd ed.; CRC Press: Boca Raton, FL, USA, 2009.

20. Bratu, M.; Vasile, O.; Dumitrescu, O. Sound-absorbing properties of composite materials reinforced with various wastes. Environ. Eng. Manag. 2011, 10, 1046-1051. [CrossRef]

21. Yang, W.; Li, Y. Sound absorption performance of natural fibers and their composites. Sci. China Technol. Sci. 2012, 55, 2278-2283. [CrossRef] 
22. Jayamani, E.; Hamdan, S.; Rahman, M.R.; Bakri, M.K.B.; Kakar, A. An investigation of sound absorption coefficient on sisal fiber poly lactic acid bio-composites. J. Appl. Polym. Sci. 2015, 132. [CrossRef]

23. Zhang, J.; Shen, Y.; Jiang, B.; Li, Y. Sound absorption characterization of natural materials and sandwich structure composites. Aerospace 2018, 5, 75. [CrossRef]

24. Zhang, S.; Li, Y.; Zheng, Z. Effect of physiochemical structure on energy absorption properties of plant fibers reinforced composites: Dielectric, thermal insulation, and sound absorption properties. Comp. Comm. 2018, 10, 163-167. [CrossRef]

25. Yang, H.S.; Kim, D.J.; Kim, H.J. Rice straw-wood particle composite for sound absorbing wooden construction materials. Bioresour. Technol. 2003, 86, 117-121. [CrossRef]

26. Maderuelo-Sanz, R.; Nadal-Gisbert, A.; Crespo-Amoros, J.; Parres-García, F. A novel sound absorber with recycled fibers coming from end of life tires (ELTs). Appl. Acoust. 2012, 73, 402-408. [CrossRef]

27. Maderuelo-Sanz, R.; Morillas, J.; Martin-Castizo, M.; Escobar, V.G.; Gozalo, G.R. Acoustical performance of porous absorber made from recycled rubber and polyurethane resin. Lat. Am. J. Solids Struct. 2013, 10, 585-600. [CrossRef]

28. Prabhu, L.; Krishnaraj, V.; Gokulkumar, S.; Sathish, S.; Ramesh, M. Mechanical, chemical and acoustical behavior of sisal-Tea waste-Glass fiber reinforced epoxy reinforced hybrid polymer composites. Mater. Today Proc. 2019, 16, 653-660. [CrossRef]

29. Tiuc, A.E.; Vermesan, H.; Gabor, T.; Vasile, O. Improved sound absorption properties of polyurethane foam mixed with textile waste. Energy Proc. 2016, 85, 559-565. [CrossRef]

30. Chen, D.; Li, J.; Ren, J. Study on sound absorption property of ramie fiber reinforced poly (L-lactic acid) composites: Morphology and properties. Compos. Part A Appl. Sci. Manuf. 2010, 41, 1012-1018. [CrossRef]

31. Lee, Y.; Joo, C. Sound absorption properties of recycled polyester fibrous assembly absorbers. Autex Res. J. 2003, 3, 78-84.

32. Koizumi, T.; Tsujiuchi, N.; Adachi, A. The development of sound absorbing materials using natural bamboo fibers. WIT Trans. Built Environ. 2002, 59, 157-166.

33. Ren, Y.H.; Sun, X.N.; Song, H. Study on the sound absorption properties of several kinds of fibers. Adv. Mater. Res. 2011, 332, 959-962. [CrossRef]

34. Bakri, M.K.B.; Jayamani, E.; Heng, S.K.; Hamdan, S.; Kakar, A. An experimental and simulation studies on sound absorption coefficients of banana fibers and their reinforced composites. Nano Hyb. Compos. 2017, 12, 9-20. [CrossRef]

35. Mamtaz, H.; Hosseini, M.; Zaki, M.; Narayana, S.; Ghassem, M.; Al-atabi, M. Acoustic absorption of fibro-granular composite with cylindrical grains. Appl. Acoust. 2017, 126, 58-67. [CrossRef]

36. Luu, H.T.; Panneton, R. Effective fiber diameter for modeling the acoustic properties of polydisperse fiber networks. J. Acoustl. Soc. Am. 2017, 141, EL96-EL101. [CrossRef]

37. Xiang, H.; Wang, D.; Liua, H.; Zhao, N.; Xu, J. Investigation on sound absorption properties of kapok fibers. Chin. J. Polym. Sci. 2013, 31, 521-529. [CrossRef]

38. Arumugam, V.; Kumar, B.; Santulli, C. Effect of fiber orientation in unidirectional glass epoxy laminate using acoustic emission monitoring. Acta Metall. Sin. 2011, 24, 351-364.

39. Jiang, S.; Xu, Y.; Zhang, H.; White, C.B.; Yan, X. Seven-hole hollow polyester fibers as reinforcement in sound absorption chlorinated polyethylene composites. Appl. Acoust. 2012, 73, 243-247. [CrossRef]

40. Abdullah, A.H.; Azharia, A.; Salleh, F.M. Sound absorption cofficient of natural fibers hybrid reinforced polyester composites. J. Teknol. 2015, 76, 31-36.

41. Jayamani, E.; Hamdan, S.; Heng, S.K.; Rahman, R. Sound absorption property of agricultural lignocellulsic residue fiber reinforced polymer matrix composites. Appl. Mech. Mater. 2014, 663, 464-468. [CrossRef]

42. Srivastava, R.K.; Dhabal, R.L.; Suman, B.M.; Saini, A.; Panchal, P. An estimation of correlation on thermo-acoustic properties of mineral wool. J. Sci. Ind. Res. 2006, 65, 232-236.

43. Reixach, R.; Rey, R.D.; Alba, J.; Arbat, G.; Espinach, F.; Mutjé, P. Acoustic properties of agroforestry waste orange pruning fibers reinforced polypropylene composites as an alternative to laminated gypsum boards. Const. Build. Mater. 2015, 77, 124-129. [CrossRef]

44. Jayamani, E.; Heng, S.K.; Bakri, M.K.; Hamdan, S. Comparative study of sound absorption coefficients of coir/kenaf/sugarcane bagasse fiber reinforced epoxy composites. Key Eng. Mater. 2017, 730, 48-53. [CrossRef]

45. Harris, C.M. Absorption of sound in air versus humidity and temperature. J. Acoust. Soc. Am. 1966, 40, 148-159. [CrossRef]

46. Knudsen, V.O. The absorption of sound in air, in oxygen, and in nitrogen-Effects of humidity and temperature. J. Acoust. Soc. Am. 1933, 5, 112-121. [CrossRef]

47. Knapen, E.; Lanoye, R.; Vermeir, G.; Lauriks, W.; Gemert, D.V. Acoustic properties of sound absorbing, polymer-modified porous cement mortars. In Proceedings of the 6th Internatioanl conference on Material Science and Restoration, MSR VI, Karlsruhe, Germany, 16-18 September 2003; Aedificatio Publishers: Freiburg, Germany, 2003; Volume 1, pp. 347-358.

48. Sakagami, K.; Kiyama, M.; Morimoto, M.; Takahashi, D. Sound absorption of a cavity-backed membrane: A step towards design method for membrane-type absorbers. Appl. Acoust. 1996, 49, 237-247. [CrossRef]

49. Dupont, T.; Leclaire, P.; Sicot, O.; Gong, X.L.; Panneton, R. Acoustic properties of air-saturated porous materials containing dead-end porosity. J. Appl. Phy. 2011, 110, 094903. [CrossRef]

50. Bies, D.H.; Hansen, C.H. Engineering Noise Control, 1st ed.; Spon Press, Taylor and Francis Group: London, UK, 1996.

51. Crocker, M.J. Handbook of Noise and Vibration Control, 2nd ed.; John Wiley \& Sons: Hoboken, NJ, USA, 2007. 
52. Qiu, X. Acoustic testing and evaluation of textiles for buildings and office environments. In Performance Testing of Textiles; Woodhead Publishing: Cambridge, UK, 2016; pp. 103-128.

53. Ballagh, K.O. Acoustical properties of wool. Appl. Acoust. 1996, 48, 101-120. [CrossRef]

54. Coates, M.; Kierzkowski, M. Thermoformable Acoustic Sheet. Acoust. Soc. Am. J. 2007, 122, 2509. [CrossRef]

55. Fatima, S.; Mohanty, A.R. Acoustical and fire-retardant properties of jute composite materials. Appl. Acoust. 2011, 72, 108-114. [CrossRef]

56. Hirabayashi, T.; McCaa, D.; Rebandt, R.; Rusch, P.; Saha, P. Application of noise control and heat insulation materials and devices in the automotive industry. SAE Tech. Paper 1995. [CrossRef]

57. Ibrahim, M.A.; Melik, R.W. Physical parameters affecting acoustic absorption characteristics of fibrous materials. Proc. Math. Phys. Soc. Egypt 1978, 46, 17-25.

58. Hakamada, M.; Kuromura, T.; Chen, Y.; Kusuda, H.; Mabuchi, M. High sound absorption of porous aluminum fabricated by spacer method. Appl. Phy. Lett. 2006, 88, 106-254. [CrossRef]

59. Jiang, W.; Zhang, Q.; Zhang, Y.; Guo, Z.; Tu, S.T. Flexural behavior and damage evolution of pultruded fibre-reinforced composite by acoustic emission test and a new progressive damage model. Int. J. Mech. Sci. 2020, 188, 105955. [CrossRef]

60. Taban, E.; Khavanin, A.; Ohadi, A.; Putra, A.; Jafari, A.J.; Faridan, M.; Soleimanian, A. Study on the acoustic characteristics of natural date palm fibers: Experimental and theoretical approaches. Build. Environ. 2019, 161, 106274. [CrossRef]

61. Shiney, A.; Premlet, B. Acoustic properties of composite coir mats. IOSR J. Appl. Phy. 2014, 6, 18-23.

62. Su, J.; Zheng, L.; Deng, Z. Study on acoustic properties at normal incidence of three-multilayer composite made of glass wool, glue and polyurethane foam. Appl. Acoust. 2019, 156, 319-326. [CrossRef]

63. Yuvaraj, L.; Jeyanthi, S.; Yogananda, A. An acoustical investigation of partial perforation in jute fiber composite panel. Mater. Today Proc. 2020, 1-6. [CrossRef]

64. Prabhakaran, S.; Krishnaraj, V.; Senthilkumar, M.; Zitoune, R. Sound and vibration damping properties of flax fiber reinforced composites. Procedia Eng. 2014, 97, 573-581. [CrossRef]

65. Jayamani, E.; Hamdan, S.; Rahman, R.; Bin Bakri, M.K. Investigation of fiber surface treatment on mechanical, acoustical and thermal properties of betelnut fiber polyester composites. Proceedia Eng. 2014, 97, 545-554. [CrossRef]

66. Gao, G.; Hu, Y.; Jia, H.; Liu, P.; Du, P.; Xu, D. Acoustic and dielectric properties of epoxy resin/hollow glass microspherecomposite acoustic materials. J. Phy. Chem. Solid 2019, 135, 109105. [CrossRef]

67. Mi, Y.; Zhu, C.; Li, X.; Wu, D. Acoustic emission study of effect of fiber weaving on properties of fiber-resin composite materials. Compos. Struct. 2020, 237, 111906. [CrossRef]

68. Zhang, Z.; Ren, F.; Liu, B.; Zhou, S. Acoustic fatigue properties investigation of plain weave C/SiC composite plate. J. Mater. Res. Technol. 2020, 9, 331-339. [CrossRef]

69. Jayamani, E.; Hamdan, S.; Bakri, M.K.; Heng, S.K.; Rahman, M.R.; Kakar, A. Analysis of natural fiber polymer composites: Effects of alkaline treatment on sound absorption. J. Reinf. Plast. Compos. 2016, 35, 703-711. [CrossRef]

70. Thierry, V.; Brown, L.; Chronopoulos, D. Multi-scale wave propagation modelling for two-dimensional periodic textile composites. Compos. Part B Eng. 2018, 150, 144-156. [CrossRef]

71. Tamas-Gavrea, D.R.; Denes, T.O. Mechanical, thermal and acoustical properties of an innovative lime-wool composite. Proceedia Manuf. 2019, 46, 402-409. [CrossRef]

72. Atiénzar-Navarro, R.; Bonet-Aracil, M.; Gisbert-Payá, J.; Rey, R.D.; Picó, R. Sound absorption of textile fabrics doped with microcapsules. Appl. Acoust. 2020, 164, 107285. [CrossRef]

73. Olcay, H.; Kocak, E.D. Rice plant waste reinforced polyurethane composites for use as the acoustic absorption material. Appl. Acoust. 2021, 173, 107733. [CrossRef]

74. Zhou, W.; Qin, R.; Han, K.; Wei, Z.; Ma, L.H. Progressive damage visualization and tensile failure analysis of three-dimensional braided composites by acoustic emission and micro-CT. Polym. Test. 2021, 93, 106881. [CrossRef]

75. Aggelis, D.G.; El Kadi, M.; Tysmans, T.; Blom, J. Effect of propagation distance on acoustic emission fracture mode classification in textile reinforced cement. Const. Build. Mater. 2017, 152, 872-879. [CrossRef]

76. Koruk, H.; Gen, G. Investigationoftheacousticpropertiesofbioluffa fiber andcomposite materials. Mater. Lett. 2015, 157, 166-168. [CrossRef]

77. Witczak, E.; Jasinska, I.; Lao, M.; Krawczynska, I.; Kaminska, I. The influence of structural parameters of acoustic panels textile fronts on their sound absorption properties. Appl. Acoust. 2021, 178, 107964. [CrossRef]

78. Tsangouri, E.; Michels, L.; El Kadi, M.; Tysmans, T.; Aggelis, D.G. A fundamental investigation of textile reinforced cementitious composites tensile response by acoustic eEmission. Cement Conc. Res. 2019, 123, 105776. [CrossRef]

79. Islam, S.; Bhat, G. Environmentally-friendly thermal and acoustic insulation materials from recycled textiles. J. Environ. Manag. 2019, 251, 109536. [CrossRef]

80. Kamble, Z.; Behera, B.K. Sustainable hybrid composites reinforced with textile waste for construction and building applications. Const. Build. Mater. 2021, 284, 122800. [CrossRef]

81. Echeverria, C.A.; Handoko, W.; Pahlevani, F.; Sahajwalla, V. Cascading use of textile waste for the advancement of fibre reinforced composites for building applications. J. Clean. Prod. 2019, 208, 1524-1536. [CrossRef]

82. Li, H.; Zhang, N.; Fan, X.; Gong, J.; Zhang, J.; Zhao, X. Investigation of effective factors of woven structure fabrics for acoustic absorption. Appl. Acoust. 2020, 161, 107081. [CrossRef] 
83. Haggui, M.; Mahi, A.E.; Jendli, Z.; Akrout, A.; Haddar, M. Static and fatigue characterization of flax fiber reinforced thermoplastic composites by acoustic emission. Appl. Acoust. 2019, 147, 100-110. [CrossRef]

84. Hariprasad, K.; Ravichandran, K.; Jayaseelan, V.; Muthuramalingam, T. Acoustic and mechanical characterisation of polypropylene composites reinforced by natural fibres for automotive applications. J. Mater. Res.Technol. 2020, 9, 14029-14035. [CrossRef]

85. Czigany, T. Special manufacturing and characteristics of basalt fiber reinforced hybrid polypropylene composites: Mechanical properties and acoustic emission study. Compos. Sci. Technol. 2006, 66, 3210-3220. [CrossRef]

86. Cherradi, Y.; Rosca, I.C.; Cerbu, C.; Kebir, H.; Guendouz, A.; Benyoucef, M. Acoustic properties for composite materials reinforced on alfa and wood fibers. Appl. Acoust. 2021, 174, 107759. [CrossRef]

87. Castagnede, B.; Aknine, A.; Brouard, B.; Tarnow, V. Effects of compression on the sound absorption of fibrous materials. Appl. Acoust. 2000, 61, 173-182. [CrossRef]

88. Wang, C.N.; Kuo, Y.M.; Chen, S.K. Effects of compression on the sound absorption of porous materials with an elastic frame. Appl. Acoust. 2008, 69, 31-39. [CrossRef]

89. Nor, M.; Ayub, M.; Zulkifli, R.; Amin, N.; Fouladi, M.H. Effect of compression on the acoustic absorption of coir fiber. Am. J. Appl. Sci. 2010, 7, 1285-1290. [CrossRef]

90. Keshavarz, R.; Ohadi, A. Effects of compression on sound absorption of transversely isotropic fibrous materials at oblique incidence. Appl. Acoustics 2013, 74, 383-395. [CrossRef]

91. Everest, F.A. Master Handbook of Acoustics, 4th ed.; McGraw-Hill: New York, NY, USA, 2001.

92. Aso, S.; Kinoshita, R. Maximum sound absorption coefficient of a fiber assembly. J. Text. Mach. Soc. Jpn. 1965, 11, 81-87. [CrossRef]

93. Lu, T.J.; Chen, F.; He, D. Sound absorption of cellular metals with semiopen cells. J. Acoust. Soc. Am. 2000, 108, 1697-1709. [CrossRef] [PubMed] 